\title{
Pore size distribution, their geometry and connectivity in deeply buried Paleogene Es1 sandstone reservoir, Nanpu Sag, East China
}

\author{
Muhammad Kashif ${ }^{1,2} \cdot$ Yingchang Cao $^{1} \cdot$ Guanghui Yuan $^{1} \cdot$ Muhammad Asif $^{3} \cdot$ Kamran Javed $^{1}$. \\ Jose Nicanor Mendez ${ }^{1} \cdot$ Danish Khan $^{1} \cdot$ Lin Miruo $^{1}$
}

Received: 29 August 2018 / Published online: 25 September 2019

(c) The Author(s) 2019

\begin{abstract}
The study of pore characteristics is of great importance in reservoir evaluation, especially in deeply buried sandstone. It controls the storage mechanism and reservoir fluid properties of the permeable horizons. The first member of Eocene Shahejie Formation (Es1) sandstone is classified as feldspathic litharenite and lithic arkose. The present research investigates the pore characteristics and reservoir features of the deeply buried sandstone reservoir of Es1 member of Shahejie Formation. The techniques including thin-section petrography, mercury injection capillary pressure (MICP), scanning electron microscopy and laser scanning confocal microscope images were used to demarcate the pores including primary intergranular pores and secondary intergranular, intragranular, dissolution and fracture pores. Mercury injection test and routine core analysis were led to demarcate the pore network characteristics of the studied reservoir. Pore size and pore throat size distribution are acquired from mercury injection test. Porosity values range from $0.5 \%$ to $30 \%$, and permeability ranges $0.006-7000 \mathrm{mD}$. Pore radii of coarse-grained sandstone and fine-grained sandstone range from 0.2 to $>4 \mu \mathrm{m}$ and $1 \mathrm{~nm}$ to $1.60 \mu \mathrm{m}$, respectively, by MICP analysis. The mineral composition also plays an important role in protecting the pores with pressure from failure. Fractured sandstone and coarse-grained sandstone consist of large and interconnected pores that enhance the reservoir porosity and permeability, whereas fine-grained sandstone and siltstone consist of numerous pores but not well interconnected, and so they consist of high porosity with low permeability.
\end{abstract}

Keywords Reservoir rock · Pore characteristics $\cdot$ Pore size distribution · Pore throat · Porosity · Permeability

\section{Introduction}

The movement of different reservoir fluids via different geological systems is mainly controlled by capillary pressure within the rock unit. The pore volume and pore throat size that relate to displacement pressure are the main components that control the reservoir characteristics (mainly permeability) of reservoir rock, and they can be evaluated by mercury

Edited by Hao Jie and Xiu-Qiu Peng

Muhammad Kashif

kashifyaqub@yahoo.com

1 School of Geosciences, China University of Petroleum, Qingdao 266580, China

2 Department of Earth Sciences, University of Sargodha, Sargodha 40100, Pakistan

3 Institute of Geology, University of the Punjab, Lahore, Pakistan injection test (Nabawy et al. 2009). Deeply buried sandstone is acting as a good reservoir that is controlled by pore size, pore structure and pore size distribution. Sandstone properties (porosity and permeability) are mainly controlled by grain size, grain sorting, shape, mineralogy and sedimentary structures as well as their environment of deposition (Saiag et al. 2016). Several diagenetic processes (physical, chemical and biological) are affecting sediments during lithification, vary with the chemistry of fluid, temperature and pressure and correlate with the burial history of the sedimentary basin (Loucks et al. 1984; Bjørlykke 2014). The interconnectivity and geometry of the pore system are greatly influenced by the diagenetic overprints (Lai et al. 2018a, b, c; Hollis et al. 2010). The intricate diagenetic alteration of the sandstone experienced throughout the geological history will alter the original pore system and exert low control on reservoir quality evolution (Lai et al. 2018a, b, c). Diagenetic modification changes the distribution and quantity of pore space, generating smaller and disconnected pore (Lai et al. 
2018a, b, c; Cook et al. 2011). Different types and various degrees of diagenesis reshape the pore structures (Lai et al. 2018a, b, c, 2015).

Mechanical compaction, cementation and the authigenic clay content are the main pore volume-controlling factors; however, fracturing, cement dissolution and framework grain are the most significant porosity-improving factors (Lai et al. 2018a, b, c, 2018b; Nabawy et al. 2009). Well-connected intergranular pores have large pore throats that contribute to permeability, whereas the subsequent dissolution pores and micropores are only connected by small pore throats that contribute less to permeability (Lai et al. 2018a, b, c). Primary porosity will be significantly reduced by mechanical and chemical compaction by authigenic minerals (Mozley et al. 2016). Cementation reduced the permeability by occluding the pores and pore throats (Lai et al. 2018a, b, c; Taghavi et al. 2006). Mercury injection capillary pressure (MICP) analysis was used to characterize the pore structures and pore size distribution. Micropores from the matrix and authigenic minerals occupy a significant proportion of the total porosity; in addition to the pore size, the permeability of reservoir sandstone is much affected by the pore throat connectivity, i.e. the pore throat radius, geometry and structure (Zou et al. 2012). Quartz overgrowth mostly fills the primary intergranular pores, reducing it to narrow, flat, sheet-like or slot-like pores between adjoining overgrowths face (Lai et al. 2018a, b, c; Soeder and Chowdiah 1990). The microscopic structure of pore throats is characterized by a tortuous pore system, small pore radius, poor connectivity and firm heterogeneity (Zou et al. 2012). Authigenic clay minerals play a significant role in decreasing the pore volume and concluding the pore apertures (Lai et al. 2018a, b, c; Yue et al. 2018). Because of their hair-like and honeycomb-like morphology, crystal habit and fibrous nature, they significantly affect the hydraulic and petrophysical properties of sandstone, thereby shaping the pore geometry (Lai et al. 2018a, b, c; Samakinde et al. 2016). Moreover, pore-bridging or pore-lining clays may decrease the permeability considerably by affecting the pore, pore throat radius and surface area, and reducing the size of the intergranular pores and turning them into micropores (Lai et al. 2018a, b, c; Schmitt et al. 2013a, b, 2015). Dissolution of detrital grains and cement is the primary process which enhances the porosity and permeability by increasing pores and pore throats (Lai et al. 2018a, b, c; Mozley et al. 2016).

The Es1 sandstone is classified as feldspathic litharenite, and lithic arkose of braided river, fluvial channels, distributary channel and lacustrine delta front facies. Core samples of seven exploratory wells are selected to study the petrographic analysis and sedimentological characteristics of Es1 sandstone. The present study focuses on pore size, structure and pore throat size characterization of deeply buried high-quality reservoir rock by advanced analytical methods.
The Es1 sandstone consists of intricate and heterogeneous composition, in which parts comprising pore throat in these heterogeneous sandstones remain poorly understood and cannot easily be charged by oil and gas (Tian et al. 2015; Xi et al. 2016). The studied sandstone consists of interbedded mudstone, and these muddy layers, cement and the muddy matrix may have a negative impact on permeability. Mineral composition, particle size and diagenesis are very significant controlling factors for the pore throat distribution within the reservoir sandstone and mainly controlled by hydrodynamic condition during sedimentation and diagenesis. Deformed or ductile mica grains, calcite cement and clay minerals create a problematic situation to block the pores and narrow the pore throat that causes to reduce the reservoir quality.

High-pressure mercury injection capillary pressure, low-pressure adsorption of $\mathrm{N}_{2}$ and $\mathrm{CO}_{2}$, porosity and permeability data have been used to obtained the quantitative pore size, pore volume, pore size distribution, surface area, porosity and permeability (Howard 1991; Ross and Bustin 2009; Chalmers et al. 2012; Schmitt et al. 2013a, b). Scanning electron microscopy (SEM) photomicrographs are used to perceive the pore size, morphology and type of pores from the nanoscale to the micron scale; quantitative parameters are difficult to obtain. MICP is useful for characterizing micro- to macroporosity $(r>50 \mathrm{~nm})$, low-pressure $\mathrm{N}_{2}$ adsorption is used for nanoporosity ( $d$ between 2 and $50 \mathrm{~nm}$ ), and $\mathrm{CO}_{2}$ adsorption for pore is having the smallest size $(d<2 \mathrm{~nm})$ (Chalmers et al. 2009; Clarkson et al. 2013). High-pressure mercury injection may give rise to the prospective risk of particle degradation, rock compressing and destruction of the pore network (Clarkson and Bustin 1996).

The main objectives of this study are to: (1) evaluate the pore structure characterization with advance integrated techniques of the Es1 sandstone of Shahejie Formation of Nanpu Sag; (2) propose the keen understanding of the contribution of different pore structures to evaluate the reservoir quality. To achieve these goals, the detailed core observation, thinsection study of core samples, SEM analysis, laser scanning confocal microscope (LSCM) analysis and MICP were used to evaluate the characterization of pore size, pore throat characteristics and pore distribution.

\section{Geological setting}

The Bohai Bay Basin is a giant basin and situated in east part of China, straddling over the North China Plain, Bohai Sea and lower Liaohe Plain, covering an area of about $20 \times 10^{4} \mathrm{~km}^{2}$. Bohai Bay Basin is a complex, petroliferous basin combined by Mesozoic and Cenozoic rifts (Allen et al. 1997; Ren et al. 2002), with Shahejie Formation and Dongying Formation as source rocks (Hao et al. 2011). The Nanpu Sag is a sub-unit of Bohai Bay Basin, and it is a 
small dustpan-shaped faulted sag that is situated in Bohai Bay Basin towards the north-eastern part of transition belt between Huanghua depression, Bozhong depression and Liaodong depression (Xu et al. 2008a, b; Chen et al. 2016; 2018). This sag covers more than $1900 \mathrm{~km}^{2}$ area, and more than half of the area lies under the Bohai Bay Basin. Structurally this sag is acting as a half-graben (Wang et al. 2002). Geologically Nanpu Sag is confined towards the north by Yanshan Mountain, Shaleitian fault to the south, Baigezhuang fault to the north-east, Matouying bulge to the west and Xinanzhuang fault to the north-west as shown in Fig. 1. Tectonically the Nanpu Sag consists of eight northeast trending structures, including Nanpu 1, Nanpu 2, Nanpu 3, Nanpu 4 and Nanpu 5 offshore structures, and Laoyemiao, Gaoshangpu and Liuzan onshore structures (Wang et al. 2002) that are shown in Fig. 1. The Nanpu Sag is famous for exploration potential of oil and gas from deeply buried rock (especially Shahejie Formation $>3500 \mathrm{~m}$ ). Geographically Shaleitian fault bounded towards the south and
Xinanzhuang-Baigezhuang (acting as boundary fault) fault to north-east. It further consists of six sub-basins including Jizhong, Huanghua, Jiyang, Liaohe-Liaodong, Bozhong and Lingqing-Dongpu depression (Gong 1997).

Drilling data for hydrocarbon exploration are a fundamental tool to evaluate the stratigraphy of the Nanpu Sag rock units. Nanpu Sag consists of thick sediment sequence of Cenozoic strata about 5000-9000 m (Guo et al. 2016), which consists of the Eocene Shahejie Formation, the Oligocene Dongying Formation, the Miocene Minghuazhen Formation, Guantao Formation and Quaternary Pingyuan Formation (Jiang et al. 2009; Guo et al. 2016) as mentioned in Fig. 2. The studied Shahejie Formation divided into three main members from top to bottom as Es1, Es2 and Es3, respectively. The studied Es1 sandstone characterized by conglomerate sandstone, coarse-grained sandstone, finegrained sandstone, with interbedded siltstone, and mudstone of a shallow lake, semi-deep lake, meandering river delta plain and delta plain facies that are shown in Fig. 3. The Es1

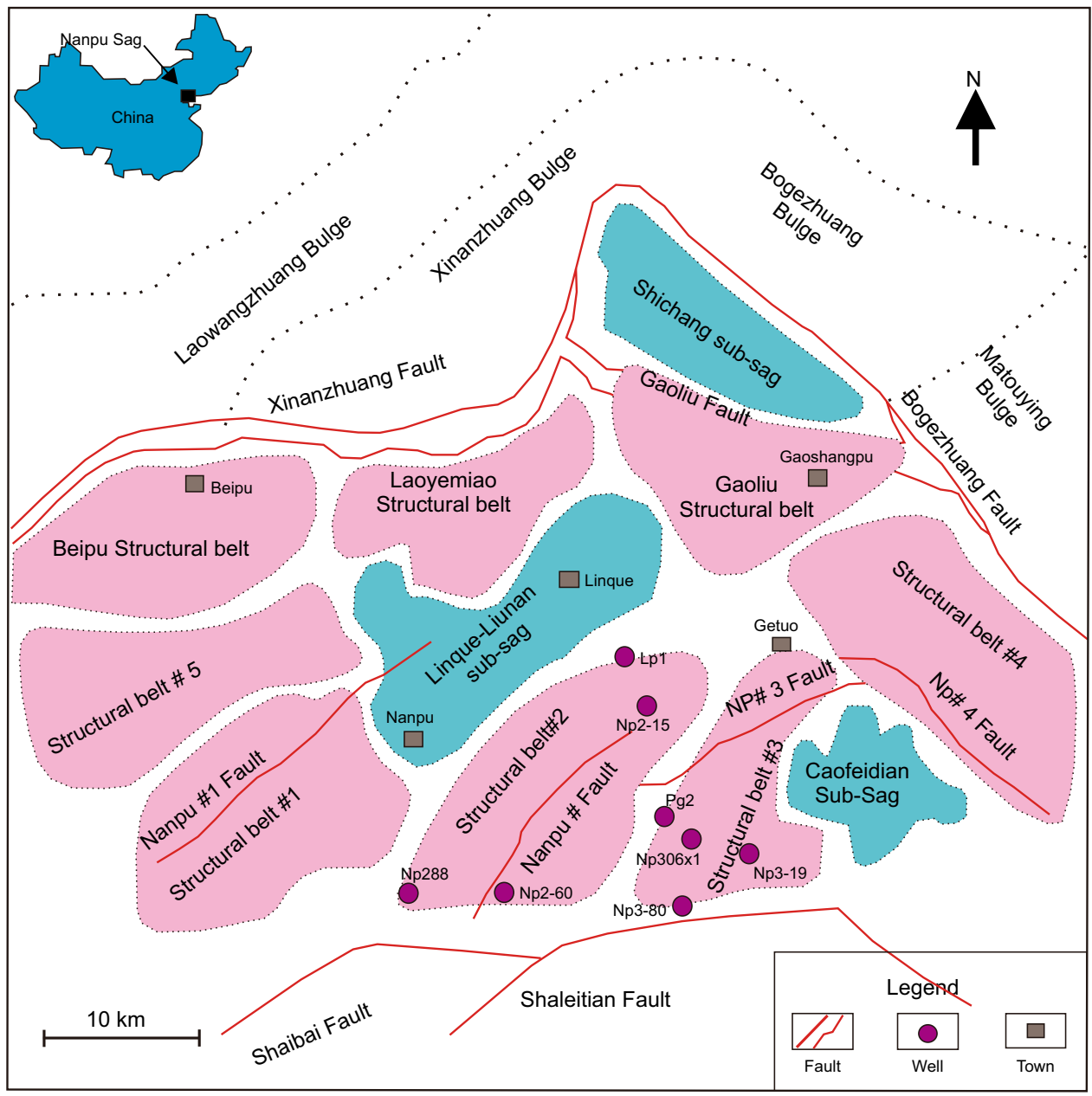

Fig. 1 Location map of the structural belt, associated bulges and structural division of Nanpu Sag, Bohai Bay Basin, China Modified after Chen et al. (2017) 


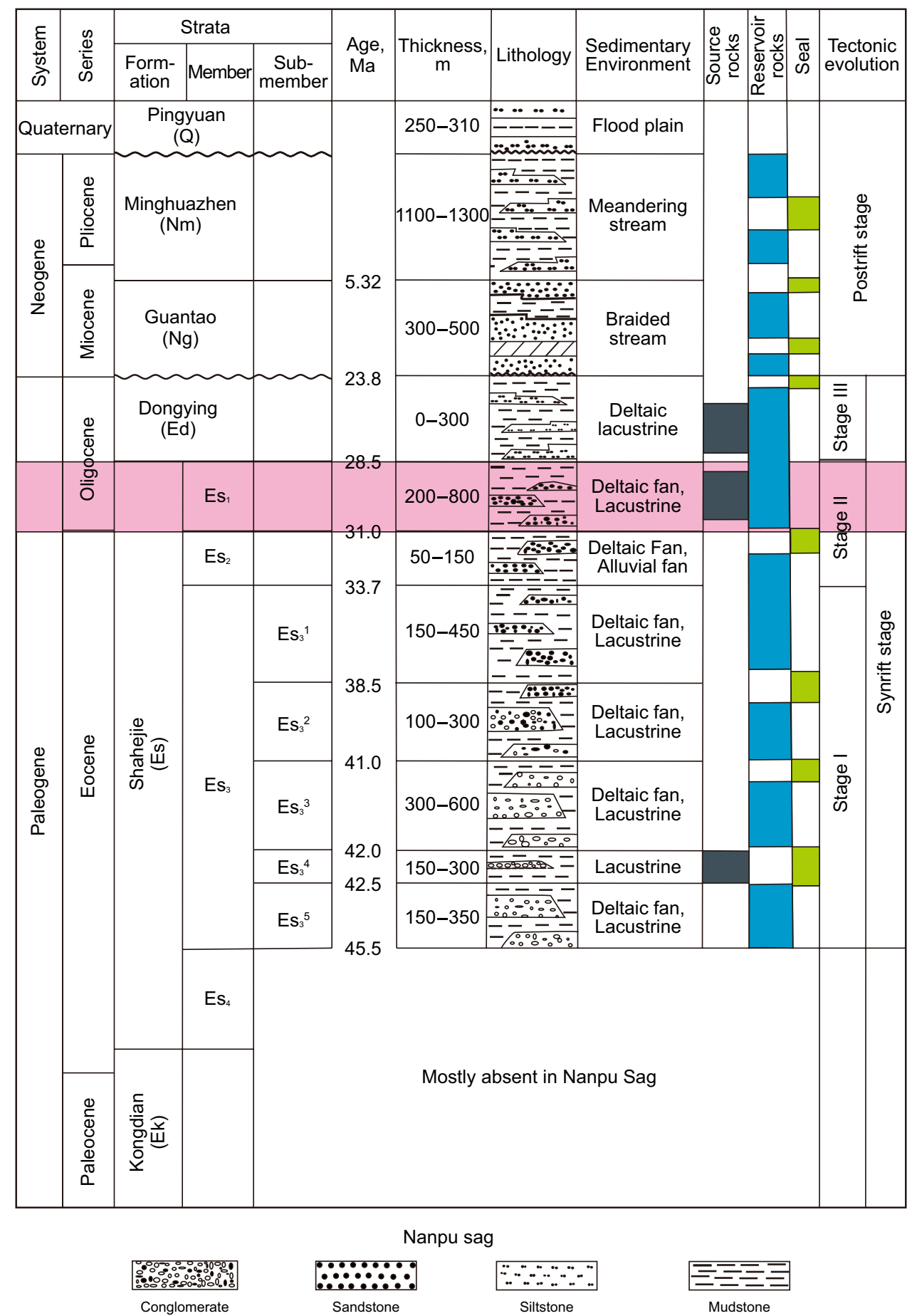

Fig. 2 Generalized Cenozoic-Quaternary stratigraphy of the Nanpu Sag showing the tectonic and sedimentary evolution stages and significant petroleum system elements. Modified after Guo et al. (2013) and Yuan et al. (2015)

member is described as shallow lacustrine lithofacies (Dong et al. 2010), and Es 2 member consists of mudstone interbedded sandstone and characterized as alluvial sediment (Guo et al. 2016). Es 3 member consists of brown mudstone with interbedded conglomerate sandstone, mudstone interbedded with siltstone and sandstone, grey oily shale interbedded with mudstone, grey and dark grey sandstone underlain by brownish mudstone interbedded with grey sand and conglomerates and characterized as Lacustrine fan delta (Wang et al. 2002; Guo et al. 2016). The Dongying Formation is a set of lacustrine deposit, Guantao Formation is characterized as a braided fluvial system, and Minghuazhen Formation 


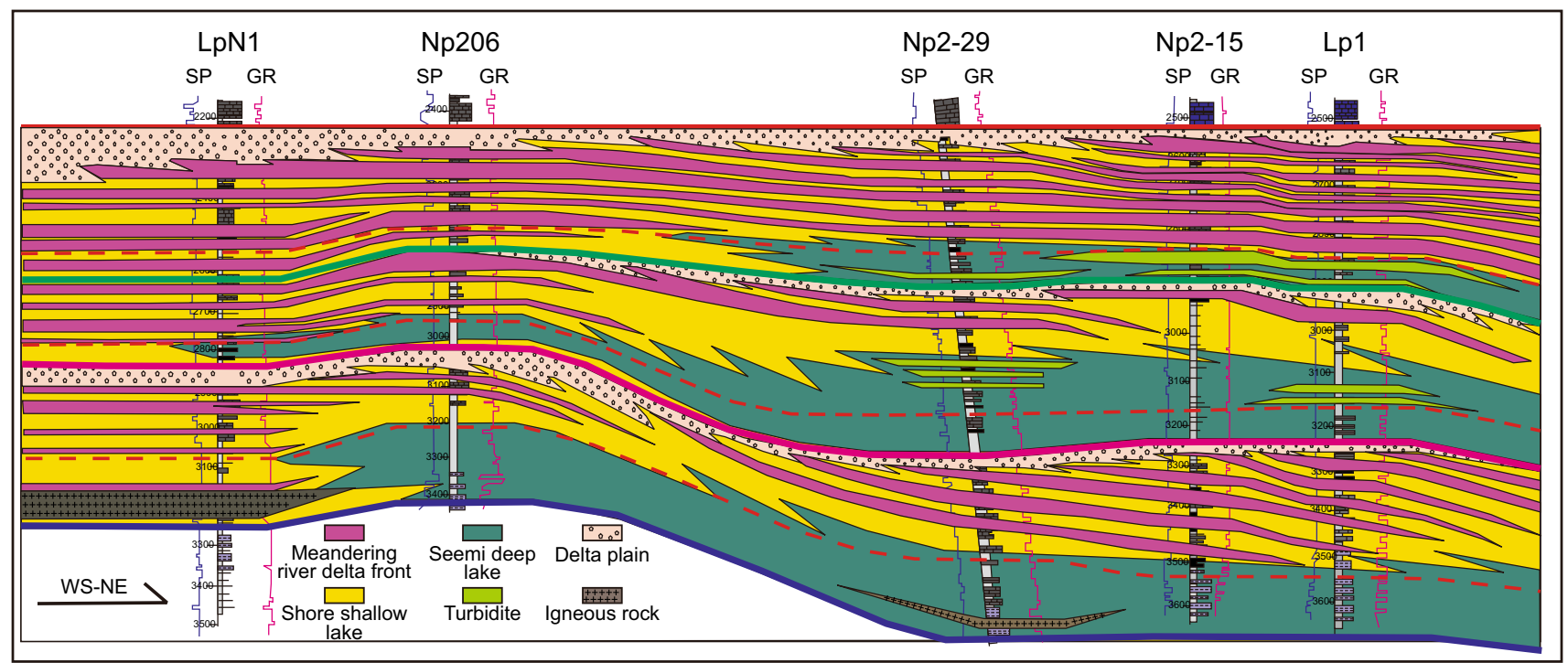

Fig. 3 Well connecting line across Np206, Lp1, Np2-15, LpN1 and Np2-29 of the various environments in Nanpu area

is a set of low-sinuosity fluvial system (Wang et al. 2002). Nowadays the overall burial depth of Shahejie Formation in Nanpu Sag area is more than $4000 \mathrm{~m}$ below sea level. The present-day geothermal gradient is $32{ }^{\circ} \mathrm{C} / \mathrm{km}\left(58^{\circ} \mathrm{F}\right)$, the average surface temperature is $14^{\circ} \mathrm{C}\left(57^{\circ} \mathrm{F}\right)$ and, the maximum temperature is $135^{\circ} \mathrm{C}\left(275^{\circ} \mathrm{F}\right)$ at greater than $4000 \mathrm{~m}$ depth. The sub-surface temperature of Ed3 and Es 1 is almost $140{ }^{\circ} \mathrm{C}$ and $170{ }^{\circ} \mathrm{C}$, respectively, and near to $200{ }^{\circ} \mathrm{C}$ for $\mathrm{Es}_{3}^{4}$. The vitrinite reflectance of the shallow $\mathrm{Ed} 3$ is $0.8 \%$ $R_{\mathrm{o}}$, and for $\mathrm{Es}_{3}^{4}$, it could be greater than $2 \% R_{\mathrm{o}}$ (Guo et al. 2013). The Ed 3 source rocks are mature to generate oil. The Es1 source rock reached hydrocarbon generation initiation at about $23 \mathrm{Ma}$, being up to high maturity to produce wet gas at that stage.

Dongying Sag is also a small secondary fault-sag depression and situated at the south-eastern side of Bohai Bay Basin. It is a dustpan-like structure with overlapping in the south and faults in the north, and it consists of an area of $5800 \mathrm{~km}^{2}$. Tectonically it is a half-graben with gentle southern slope and faulted northern margin. Laterally this sag is further subdivided into several secondary structural units, such as the northern steep slope zone, middle uplift belt, the Lijin, Minfeng, Niuzhuang trough zone, Boxing sub-sag and southern gentle zone (Zhang et al. 2014). The significant hydrocarbons generated source rock in Dongying Sag are $\mathrm{Es}_{3}^{3}$ (dark shale with 100-400 m) and $\mathrm{Es}_{4}^{1}$ (dark shale with mudstone 100-300 m) sub-members of Paleogene Shahejie Formation. These two members are the main aims of shale oil exploration in the Bohai Bay Basin. The sedimentary succession and regional history of the sag are divided into syn-rift and post-rift stages (Xie et al. 2006). The $\mathrm{Es}_{3}^{3}$ (humid lacustrine environment) and $\mathrm{Es}_{4}^{1}$ (saline environment) were deposited during the syn-rift stage. Dongying Sag area experienced multistage structural crusade that gave rise to intricate structures that dip north and derive from west to east. The latter established a NW tendency and a sinistral shear fault, called the Shicun fault, in the south of Caoqiao area. The Shicun fault is a boundary fault of Guangrao salient crossing Lijin Sag, Boxing Sag and Niuzhuang Sag. The stratigraphy is consisting of the Paleogene sequence into five formations, i.e. Kongdian Formation (EK), Shahejie Formation (ES), Dongying Formation (Ed), Guantao Formation $(\mathrm{Ng})$ and Minghuazhen Formation $(\mathrm{Nm})$. The Shahejie Formation (Es) consists of source and reservoir members. The main source rock members are $\mathrm{Es}_{3}^{3}$ and $\mathrm{Es}_{4}^{1}$ (Zhu and Jin 2003). Within the Dongying Sag, the maximum burial depth of Shahejie Formation is $5000 \mathrm{~m}$ (Guo et al. 2012; Song et al. 2009). The present-day geothermal gradient is $34{ }^{\circ} \mathrm{C} / \mathrm{km}$, and the maximum temperature is $180^{\circ} \mathrm{C}$ at this depth (Wang 2010). Total organic carbon content within the source rocks is $0.5 \%-18.6 \%$ with type I and type II kerogen (Guo et al. 2010). The $R_{\mathrm{o}} \%$ (vitrinite reflectance) varies from $0.35 \%$ to $1.5 \%$ from 2000 to $5000 \mathrm{~m}$, representing source rock is slight mature to mature (Guo et al. 2012).

\section{Materials and methods}

A comprehensive study was a prerequisite including petrographic thin-section observation and petrophysical analyses of core cutting samples. Wireline log data, thin-section petrography, SEM analysis, LSCM analysis and MICP analysis are the primary methods that are used to evaluate the pore characteristics of Es1 sandstone. Core samples are collected from seven wells; among them, 120 core plugs were selected for thin sections at a depth interval of 2490-4500 m. 
On the basis of core observation, samples were collected and analysed to investigate pore characteristics from core intervals. In total, 140 reservoir porosity and permeability data points and well logging data were obtained from Shengli Oilfield Company, China. Petrographic thin sections were detailedly studied with the help of an optical polarizing microscope to compute and interpret grain size, their type, fabric, compaction, cement type, sedimentary features and pore size distribution. Thin sections were partially stained by Alizarin red S and K-ferricyanide to identify carbonate minerals using Dickson's technique (1966). Thin sections are studied under Zeiss Axioscope POL digital transmission microscope for rock mineralogy, pore characteristics and diagenesis. COXEM EM- $30^{+}$scanning electron microscope (SEM) equipped with an energy-dispersive $\mathrm{X}$-ray spectrometer (EDX) was used to interpret the clay minerals, cement types, various pore spaces and their impact on petrophysical properties, diagenetic features and other material that affect the whole pore network of the reservoir. The SEM equipped with a secondary electron, energy-dispersive $\mathrm{X}$-ray detector and backscatter electron was used to image the pore system and compositional variation. For this purpose, twenty-four core samples were prudently chosen for SEM analysis. MICP measured pore throat size distribution; for this purpose, 22 samples were selected to analyse the mercury injection experiments using a micrometric Autopores apparatus; porosity was assessed by mercury injection that was used for special core analysis, and inoculation of helium at $120 \mathrm{kPa}$ pressure by helium pycnometer is used for routine core analysis. These types of injection test were conducted using a mercury porosimeter. Their diameter measures the number of pores as megapores/supercapillary $(D \geq 60 \mu \mathrm{m})$, macropores/capillary pores $(60 \mu \mathrm{m}>D \geq 8 \mu \mathrm{m}$; and mesopores, $8 \mu \mathrm{m}>D \geq 0.4 \mu \mathrm{m})$ and sub-capillary/ micropores $(D<0.4 \mu \mathrm{m})$ (Nabawy et al. 2009).

Twenty samples were selected for a laser scanning confocal microscope (LSCM) to evaluate the pore, pore size and their connectivity. The operating conditions were done in a Zeiss microscope equipped with AxioCam 506 colour (LSM 700), was maintained at $10 \mathrm{kV}$ beam energy and $250 \mu \mathrm{A}$ beam current.

All these samples except MICP were prepared, analysed and interpreted at different laboratories of the School of Geosciences, China University of Petroleum, Huangdao (Qingdao), whereas MICP was done at Analytical Laboratory of the CNN Beijing Research Institute of Uranium Geology.

\section{Results}

\subsection{Microscopic studies}

The studied Es1 member of Shahejie Formation mostly consists of fine-grained, coarse-grained and conglomerate sandstone with interbedded mudstone. Thin-section petrographic study indicates that Es1 member is primarily comprising of the detrital component and mainly composed of quartz (10\%-70\% bulk volume), feldspar, micas and different rock fragments with a mixed fraction. The petrographic thinsection study indicates that the studied sandstones are classified as lithic arkose and feldspathic litharenite as shown in Fig. 4. Mudstone occurs in subordinate forms and clayassociated minerals and carbonate minerals are abundant in fine-grained sandstone, siltstone and mudstone. Sandstone comprises conglomerate sandstone, coarse-grained sandstone, medium-grained sandstone and fine-grained sandstone. Sandstone detrital grains are poorly sorted to sorted and angular to sub-angular and sub-rounded grains. Moreover, grains shows concavo-convex to line contact and represents the intensity of the compaction. Feldspar present in the form of K-feldspar and albite (Na-feldspar) and ranges from $12 \%$ to $65 \%$ with an average of $38.5 \%$. Albite shows little variation concerning a depth that K-feldspar disappears with concerning extent.

Beside quartz and feldspar, the sandstone consists of rock fragments and mica that has been identified by thin-section studies. Rock fragments are present $8 \%-65 \%$ with an average of $38.4 \%$. Chert is also observed in the thin section from $0.5 \%$ to $8 \%$ with an average of $3.7 \%$ and appears as pure quartz due to their constant lucidity under a plane polarizing microscope. The bulk XRD data show that samples contain quartz, $\mathrm{k}$-feldspar, albite, calcite and dolomite and pyrite existing in a small amount as well as clay minerals as a whole. Based on XRD data, the kaolinite and mixedlayer illite/smectite are common in the studied sandstone followed by illite. Rendering to pore type and pore percentage, the studied sandstone samples consist of homogeneous and heterogeneous pores. Among them, homogeneous pores are characterized mainly by vuggy and intergranular macropores and mesopores. The homogeneous pores are described by pore types, mineralogical texture and distribution, whereas heterogeneous pores are distinguished mainly intergranular mesopores, dissolution pores and micropores (matrix). The heterogeneity in mineralogical texture is due to the presence of carbonate cement, iron oxide and other constituent, so some of the studied samples are described by heterogeneity in pore size distribution. 


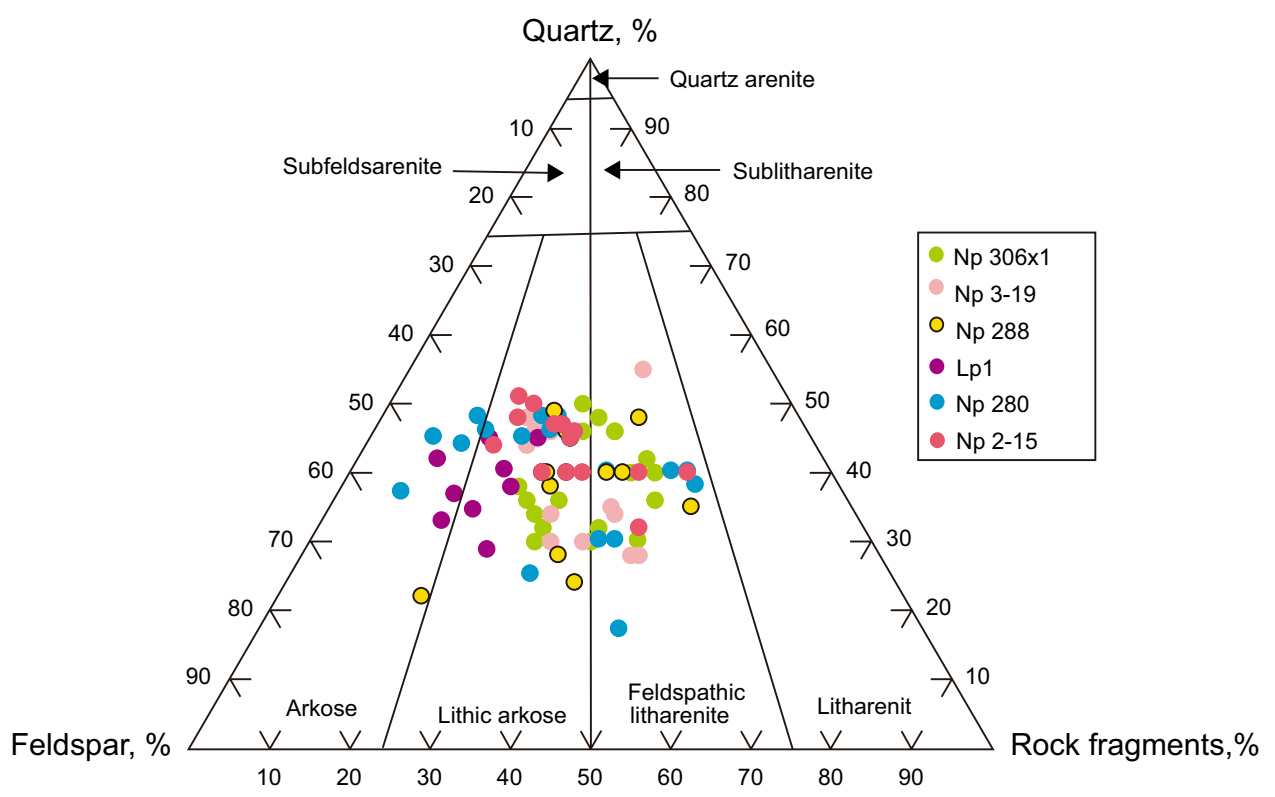

Fig. 4 Rock composition of Es1 sandstone (ternary plot refer to the sandstone classification standard of Folk 1974)

\subsection{Capillary pressure test}

Mercury injection capillary pressure was performed on deeply buried high-quality porous and permeable sandstone. An advanced increment of the applied pressure was escorted by an advanced superior increase in the mercury incursion inside the pore. It is concluded that if the pore throats are smaller, then higher pressure is required to flow. The studied Es1 sandstone exhibits good to excellent porosity varying from $17.9 \%$ to $29.5 \%$ that is presented in Table 1 .

On the basis of diameter, the studied formation consists of supercapillary/megapores, capillary pores (mesopores and macropores) and sub-capillary/micropores. The studied Es1 sandstone is consisting well to moderate pore connectivity, so that is why permeability of reservoir is also good depending upon pore size and pore throat radius. Mostly bigger pores with higher pore connectivity have good porosity and permeability, and smaller pore with moderate to lower pore connectivity have poor reservoir characteristics. Well 3-80 (coarse-grained sandstone, $4534.7 \mathrm{~m}$ ) and well Np306x1 (conglomerate sandstone, $4218.7 \mathrm{~m}$ ) have pore throat radius of 0.006 to $>63 \mu \mathrm{m}$, and they consist of megapores, macropores, mesopores and micropores. The sample comprises of bigger pore throat radius and well connectivity of the pores, so the permeability curve shows the high permeability of these well samples as shown in Fig. 6a, b. Well Np306x1 (coarse-grained sandstone, $4234.2 \mathrm{~m}$ ) and well Np280 (medium-grained sandstone, $3603.95 \mathrm{~m}$ ) have pore throat radius of 0.006 to $>3.2 \mu \mathrm{m}$, and they consist of mesopores and micropores. The sample consists of an average pore throat radius and connectivity of pores is good, so the permeability curve shows the moderate to good reservoir characteristics shown in Fig. 6c, d. Well Np2-15 (finegrained sandstone and siltstone, $3617 \mathrm{~m}$ ) and well Np3-19 (fine-grained sandstone, $4232.59 \mathrm{~m}$ ) have pore throat radius of 0.006 to $<0.63 \mu \mathrm{m}$, and they consist of mesopores with

Table 1 Fractions of mercury porosity values of different pore sizes (based on Nabawy et al. 2009) attained from the mercury injection test

\begin{tabular}{|c|c|c|c|c|c|c|c|}
\hline Sample no. & Depth, m & $\begin{array}{l}\text { Macropores, } \\
\%\end{array}$ & $\begin{array}{l}\text { Macropore } \\
\text { threshold, } \mu \mathrm{m}\end{array}$ & Mesopore, \% & $\begin{array}{l}\text { Mesopore } \\
\text { threshold, } \mu \mathrm{m}\end{array}$ & Micropores, \% & $\begin{array}{l}\text { Porosity measured } \\
\text { by } \mathrm{Hg} \text { injection }\end{array}$ \\
\hline Np3-80-1 & 4534.7 & 26 & 8.4 & 53 & 0.42 & 21 & 29.5 \\
\hline Np280-5 & 3503.95 & 25 & 8.4 & 65 & 0.42 & 20 & 28.4 \\
\hline Np288-6 & 3725.4 & 30 & 8.4 & 49 & 0.42 & 21 & 26.8 \\
\hline Np3-19-7 & 4232.59 & 16 & 8.4 & 41 & 0.42 & 43 & 17.9 \\
\hline Np2-15-8 & 3617 & 24 & 8.4 & 41 & 0.42 & 35 & 19.2 \\
\hline Lp1 & 2934.20 & 27 & 8.4 & 53 & 0.42 & 20 & 23.7 \\
\hline Np306x1-10 & 4218.70 & 28 & 8.4 & 54 & 0.42 & 17 & 26.8 \\
\hline
\end{tabular}


abundant micropores. The sample comprising of average pore throat radius and connectivity of pores is fair to good, so the permeability curve shows the moderate to poor reservoir characteristics that is shown in Fig. 6e, f.

\subsection{Pore system}

Types of pores, their shape and their connectivity depend on compaction, mineral dissolution, precipitation and organic matter degradation/maturation and hydrocarbon generation. Mechanical compaction destroys the pore spaces, and dissolution promotes the creation of pores in siliciclastic sandstone (Mondol et al. 2007; Loucks et al. 2012). Furthermore, asphaltic filling and carbonate cement precipitation significantly reduce the pore size and reduce the porosity (Rexer et al. 2014). The studied sandstone is consisting of macropores, mesopores and micropores. Pores are characterized as macropores $(d>50 \mathrm{~nm})$, mesopores $(d=2-50 \mathrm{~nm})$ and micropores $(d<2 \mathrm{~nm})$ (Rouquerol et al. 1994). Macroto nanopore system is developed within the studied samples. According to Loucks et al. (2012), pore classification is used to classify the pore spaces into: (a) intergranular pores, (b) matrix pores and secondary intragranular pore among grains and mineral crystal, and (c) fracture pores (Table 2).

Various types of pores are identified in conglomerate sandstone, coarse-grained sandstone, medium-grained sandstone, fine-grained sandstone as well as siltstone that are presented in Fig. 7. The pores are identified under a plane polarizing microscope and SEM. Conglomerate sandstone, coarse-grained sandstone, medium-grained sandstone and fine-grained sandstone are mostly consisting of primary intergranular pores, dissolution pores and fractures pores. Primary intergranular pores are present between detrital grains and were preserved after compaction and cementation that are shown in Fig. 7a, b. Carbonate cement, filling clay minerals and ductile deformation (grain flow) as shown in Figs. 5a, c, d, f; $8 \mathrm{f}$ reduce the pore space and decree the reservoir characteristics (Kashif et al. 2019). Figures 5b, e and 8a show the dissolution pores created by leaching of unstable minerals and rock fragments and enhance the interparticle secondary pores. The pores are varied in shape and size depending on the geometrical arrangements of the grains. Pores appear as elongated surrounded by rigid grains/particles. Other pores include triangular primary pores between rigid grains, which are partially filled by clays and organic matter and authigenic minerals. These pores are acting as a pathway due to their large pore size and pore connectivity. Dissolution pores are diagenetic pores, formed within the low-resistance fragments, minerals, particles, feldspar grains and carbonate cement that are common in the studied sandstone as shown in Figs. 5b, e; 7b; and $8 \mathrm{a}, \mathrm{c}$. Some micro- to nanoscale pores is also observed within clays aggregates due to the transformation of unstable clay minerals. Some thin section shows microfractures, interpreted as compaction fractures and dehydration created shrinkage cracks, hydrocarbon expulsion generated fractures. Microfractures also formed due to overpressure and pressure solution (stylolites) and natural brittle fractures (Zhang et al. 2018).

\subsection{Pore structures}

\subsubsection{Pore size and pore throat distribution}

Besides the reliance of capillary pressure on reservoir characteristics, former scientists deliberated that the shape of the capillary pressure curve is mostly affected by the pore geometry (Rose and Bruce 1949; Vavra et al. 1992). MICP curves show capillary pressure within the reservoir sandstone is appropriate representatives for quantification of pore geometry and integration of dynamic data into reservoir models. MICP experiments on the selected core samples show connected pore size distributions from Es1 sandstones. At least six out of eight samples show bimodal pore size distribution

Table 2 Porosity and pore volume obtained by helium porosimetry

\begin{tabular}{|c|c|c|c|c|}
\hline \multirow[t]{2}{*}{ Sample no. } & \multirow[t]{2}{*}{ Depth, m } & \multirow[t]{2}{*}{ Lithology } & \multicolumn{2}{|l|}{ Helium pycnometry } \\
\hline & & & Pore volume, $10^{-3} \mathrm{~cm}^{3} / \mathrm{g}$ & Porosity, \% \\
\hline $1-\mathrm{Np} 3-80$ & 4534.70 & Medium-grained sandstone & 1.544 & 13.6 \\
\hline $2-\mathrm{Np} 306 \mathrm{X} 1$ & 4223.35 & Coarse-grained sandstone & 2.003 & 16.7 \\
\hline $3-\mathrm{Np} 306 \mathrm{X} 1$ & 4220.76 & Coarse-grained sandstone & 1.942 & 15.9 \\
\hline 4-Np280 & 3503.20 & Conglomerate sandstone & 1.997 & 21.1 \\
\hline $5-\mathrm{Np} 280$ & 3503.95 & Coarse-grained sandstone & 1.362 & 15.2 \\
\hline 6-Np3-19 & 4232.59 & Medium-grained sandstone & 1.419 & 10.4 \\
\hline $7-\mathrm{Np} 2-15$ & 3617.00 & Siltstone & 0.756 & 6.3 \\
\hline $8-\mathrm{Np} 306 \mathrm{X} 1$ & 4234.20 & Fine-grained sandstone & 0.741 & 7.2 \\
\hline 9-Np306X1 & 4218.70 & Siltstone & 0.602 & 5.3 \\
\hline
\end{tabular}



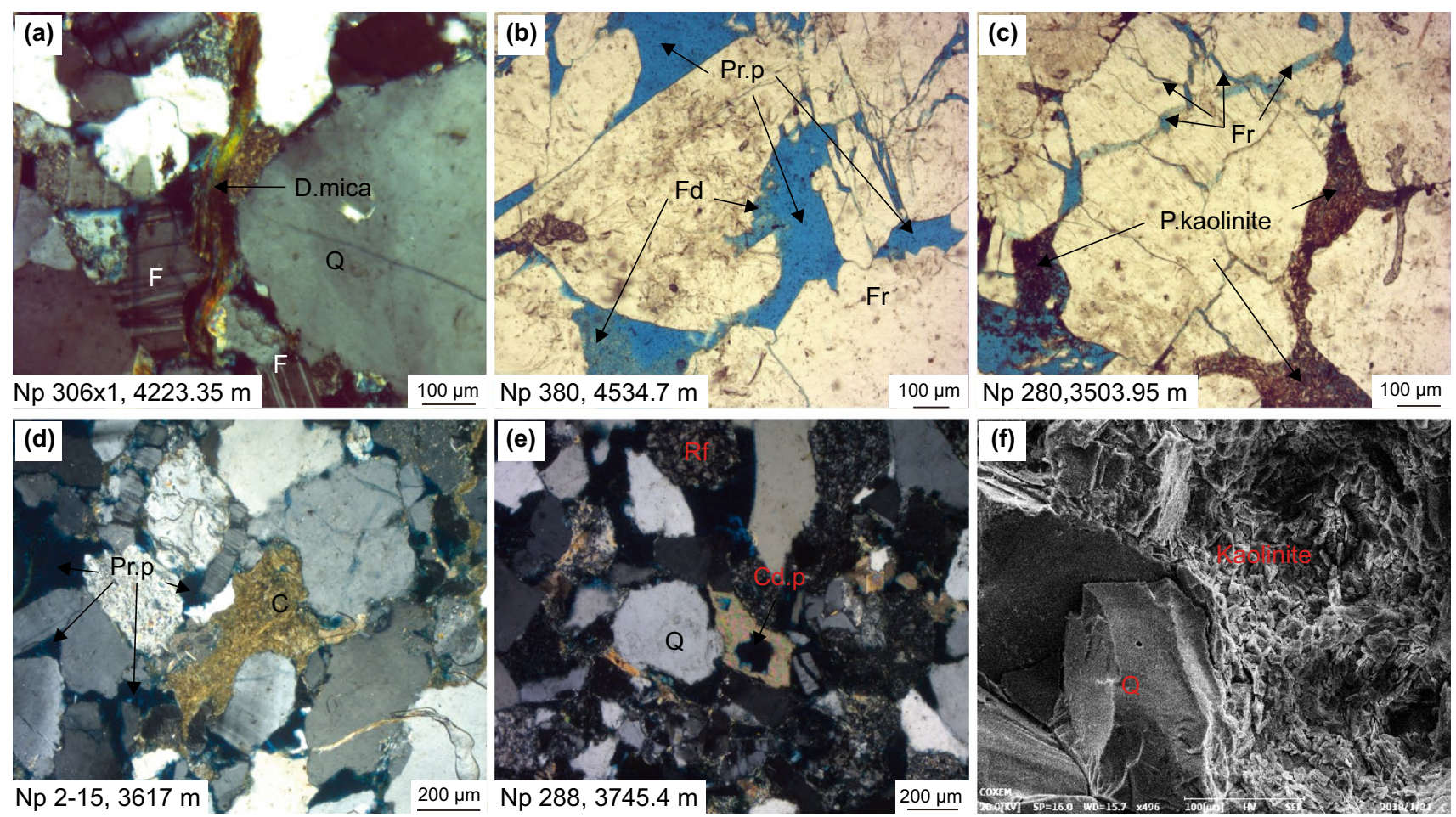

Fig. 5 Petrographic thin-section and SEM photograph shows the pore characteristics; a ductile mica flow, caused to reduce the pore size; $\mathbf{b}$ primary intergranular pores, fractures and partially to complete feldspar dissolution and enhance the rock quality; c clay mineral (kaolinite) fills the primary pores and reduces the reservoir quality; d primary intergranular pores; pores are filled by calcite cement and reduces the reservoir characteristics; e calcite cement is dissolved and creating pores; $\mathbf{f}$ SEM image shows the kaolinite filling the pore space and reduces the reservoir quality; $Q$ quartz; $D$. mica ductile mica; $F$ feldspar, $F d$ feldspar dissolution; $F r$ fractures; $P r . p$ primary pores; $P$. kaolinite pore filling kaolinite; $C$ calcite, $C d$. $p$ calcite dissolution pores; $R f$ rock fragment
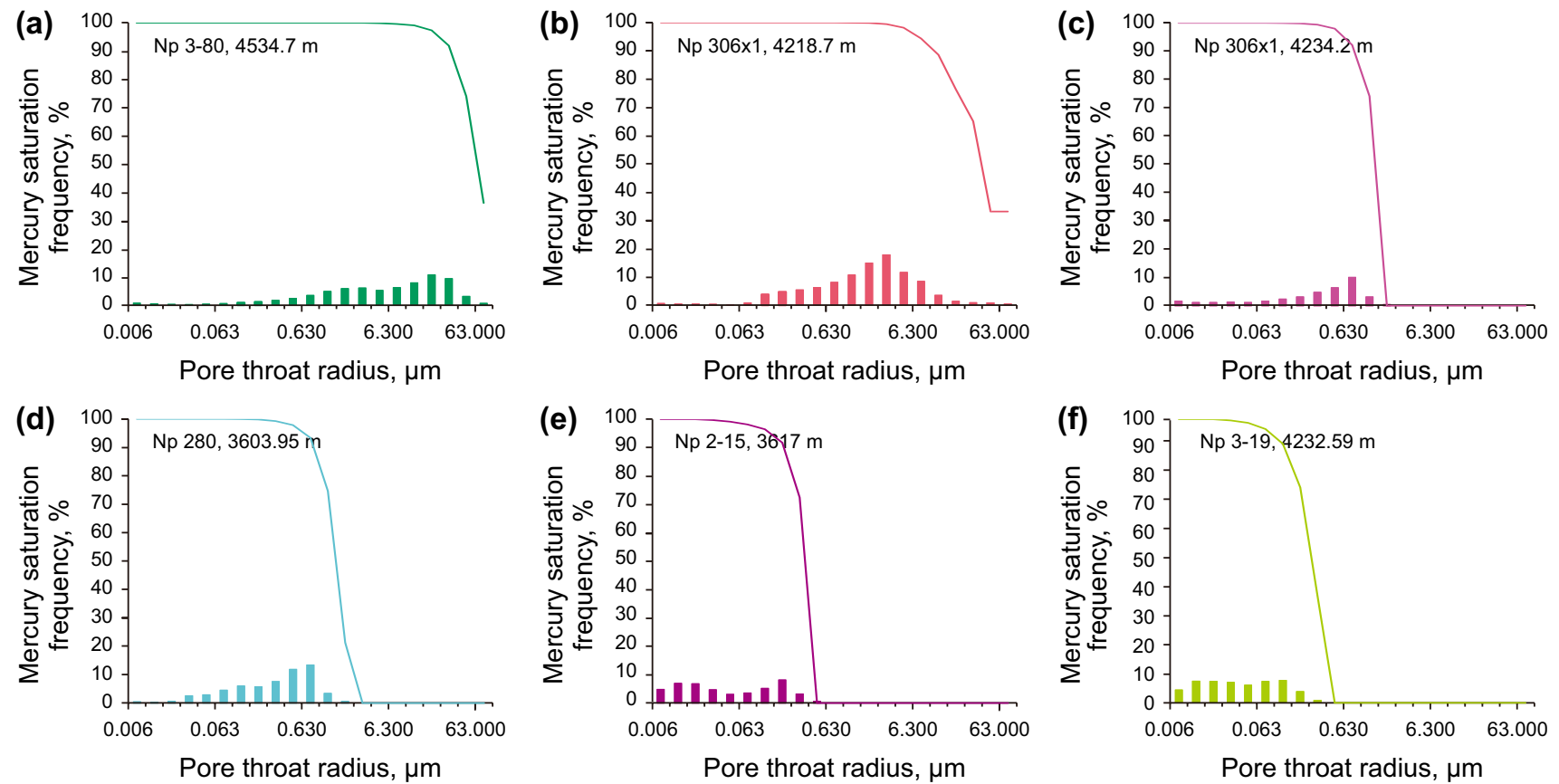

Fig. 6 Mercury saturation bar chart and permeability contribution value accumulation curve in Nanpu wells Bohai Bay Basin 

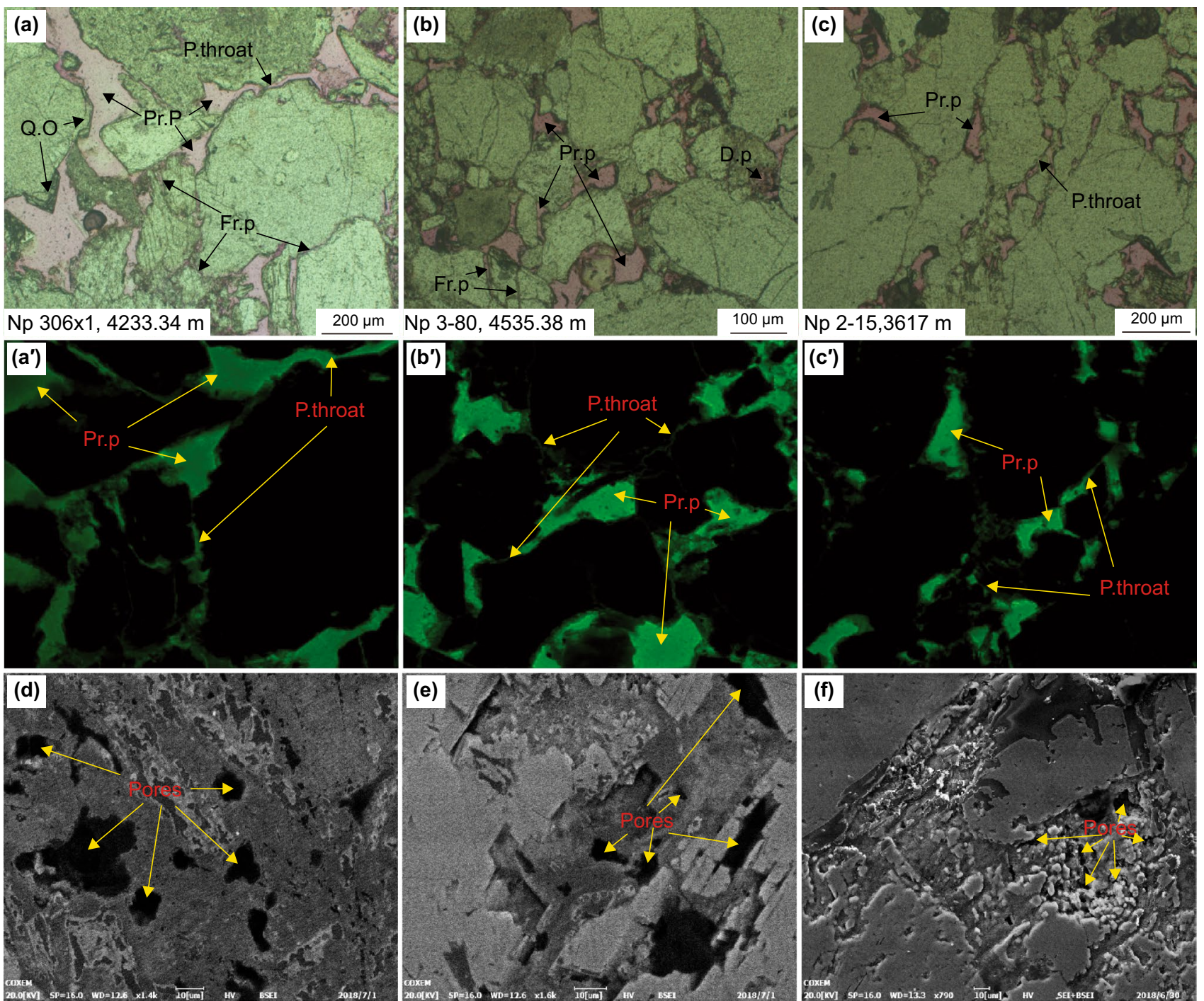

Fig. 7 Representation of primary pores and secondary pores under a polarizing microscope, a laser scanning microscope, and SEM and BSEM photographs. a Primary intergranular pores, with pore throat and quartz overgrowth; $\mathbf{b}$ primary pores, dissolution pores and fractures pores; pore size is smaller than $\mathbf{a} ; \mathbf{c}$ primary pores, fractures and pore throat, size of pore is smaller than $\mathbf{a}$ and $\mathbf{b} ; \mathbf{a}^{\prime}-\mathbf{c}^{\prime}$ laser scanning confocal microscopic images of $\mathbf{a}, \mathbf{b}$ and $\mathbf{c} ; \mathbf{d}$ BSEM image showing the larger pores; e BSEM image shows the primary and dissolution pores in feldspar; $\mathbf{f}$ SEM and BSEM combined image shows the smaller minerals/intercrystalline minor pores. Pr. $p$ primary pores; $Q$. $o$ quartz overgrowth; $P$. throat pore throat; $D p$ dissolution pores; Fr. $p$ fracture pores

comprised of macropores and mesopores. Most of the macropores (25\%-30\%) lie between 1 and $10 \mu \mathrm{m}$ which corresponds to intergranular and dissolution pores. Some samples show $20 \%-25 \%$ pore volume with pore throat sizes between 0.1 and $1 \mu \mathrm{m}$ which corresponds to intercrystalline pores in clay and carbonate cement. Nearly all samples show a small fraction $(20 \%)$ of mesopore volume with pore throat sizes of $<0.1 \mu \mathrm{m}$ which corresponds to intercrystalline pores in clay. Details of pore throat sizes of $<0.006 \mu \mathrm{m}$ are not available from MICP experiments.

Samples Np306x1, 4218.7 m, and Np3-80, 4534.7 m, are consisting of coarse grains and medium to well-sorted grains, and well-developed pores in thin-section as well as
SEM images are shown in Figs. 7a, d; 8a, g. Their primary drainage curves show good reservoir quality especially permeability as shown in Figs. 6a, b. Np306x1, 4223.35 m, and $\mathrm{Np} 280,3503.95 \mathrm{~m}$, have medium to coarse grain and are moderately sorted, and their primary drainage curve indicates good reservoir characteristics (high permeability) (Figs. 6c, d; 7b, e; 8b). Moderate reservoir consists of moderate to well-sorted grains of heterogeneous nature as shown in thin section in Figs. 7b; 8b. On the other hand, samples NP2-15, $3617 \mathrm{~m}$, and Np3-19, $4232.59 \mathrm{~m}$, are poorly sorted, compacted and mostly consisted of clay matrix and carbonate cement with low porosity (Figs. 5c, d, f; 8f) that causes to clog the pores, due to that most of the pore throats lie 

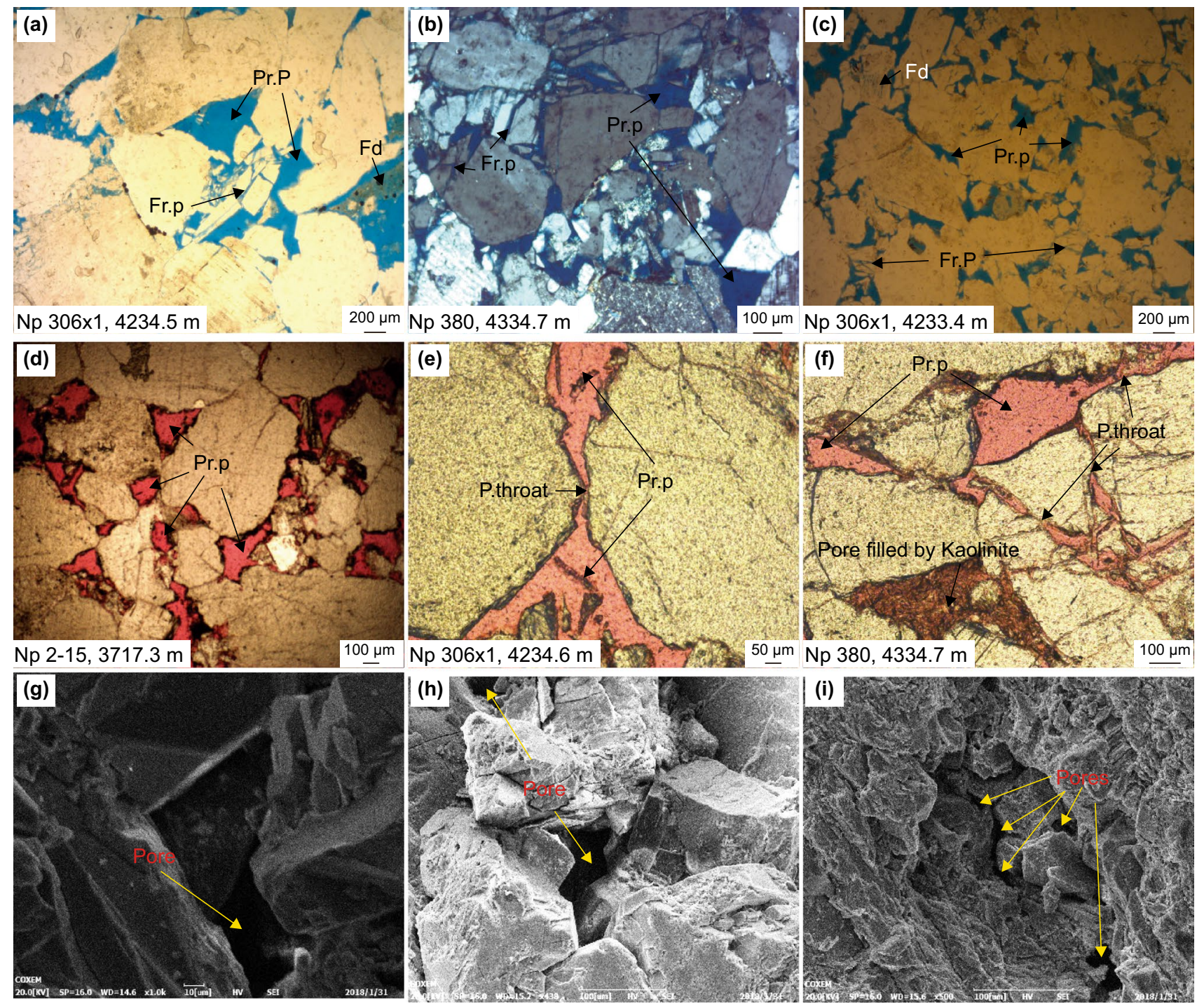

Fig. 8 Representation of primary pores, secondary pores, pore interconnectivity, under polarizing microscope and SEM. a Larger primary intergranular pores, with dissolution pores and fractures pores with pore throat; $\mathbf{b}$ primary pores and fractures pores, pore size is smaller than $\mathbf{a}$; $\mathbf{c}$ primary intergranular pores; $\mathbf{d}$ large primary intergranular pores with regular pore throat; $\mathbf{f}$ primary intergranular pores, pore filled by kaolinite clay and pore throat; $\mathbf{g}$ large pore under SEM; $\mathbf{h}$ intermediate pores under SEM; i smaller pores under SEM;. Pr. $p$ primary pores; $P$. throat pore throat; $D p$ dissolution pores; Fr. $p$ fracture pores

between $0.1 \mu \mathrm{m}$ to $1 \mu \mathrm{m}$ in size (Fig. 11). It shows the lower pore size spectrum than other samples. Due to poorly sorted and heterogeneous nature, the initial drainage curve moves up higher and indicates poor reservoir quality. The ejection curves show that mercury fails to recover from samples completely down to 0.80-0.90 MPa mercury pressure. Mercury is still trapped in the pores from $22 \%$ to $78 \%$ as shown in Fig. 11. The main reason of mercury not recovered may be due to some chemical or capillary forces that hold mercury in pores or due to the destruction of the pore network. MICP is a useful method to evaluate pore size distribution. Macropores are the parts of the pore throat with Mp threshold $>D \geq 8.4 \mu \mathrm{m}$, mesopores are pore throats with a diameter within the range of $8.4 \mu \mathrm{m}>D \geq 0.45 \mu \mathrm{m}$, and micropores are the pore throat with a diameter $<0.4 \mu \mathrm{m}$ (Nabawy et al. 2009). In MICP analysis, macropores contribute $25.33 \%$, mesopores $52.66 \%$ and micropores $23 \%$ on average of total pore volume with variation in different wells.

The specific surface area of the sample is measured by Brunauer, Emmett and Teller (BET) including pore size distribution. It measures the surface area and open pores of macroporous and mesoporous materials, as well as pore volume and area distribution that characterize porosity below the effective range of mercury intrusion porosimetry. The pore throat structure parameters were gained by $\mathrm{N}_{2}$ adsorption analysis, i.e. average pore volume, pore volume and 
BET surface area (Table 3). The SBET (specific surface area) of selected samples was calculated by BET equation (Brunauer et al. 1938).

$\frac{1}{v\left[\left(\rho_{\mathrm{o}} / \rho\right)-1\right]}=\frac{c-1}{v_{\mathrm{m}} c}\left(\frac{\rho}{\rho_{\mathrm{o}}}\right)+\frac{1}{v_{\mathrm{m}} c}$,

where $\rho$ and $\rho_{\mathrm{o}}$ are the equilibrium and the saturation pressure of the adsorbates at the temperature of adsorption, respectively, $v$ is the adsorbed gas quantity and $v m$ is the monolayer adsorbed gas quantity. $C$ is the BET constant.

$c=\exp \left(\frac{E_{1}-E_{\mathrm{L}}}{R T}\right)$,

where $E_{1}$ is the heat of adsorption for the first layer and $E_{\mathrm{L}}$ is a second higher layer.

The SBET (specific surface area) values range from 5540.27 to $115.49 \mathrm{~m}^{2} / \mathrm{g}$. The specific pore volume is resolute by Barrette-Joyner-Halenda (BJH) theory (Barrett et al. 1951), and it ranges from 2.0 to $0.073 \mathrm{~cm}^{3} / \mathrm{g}$.

\subsubsection{Pore connectivity}

Es1 sandstone consists of a different type of pores that are mostly connected, which enhances the reservoir characteristics. The pore connectivity of Es1 sandstone in Nanpu Sag was characterized by using SEM and LSCM to qualitatively establishing pore space and analysing pore throat distribution and connectivity. Overall experimental results indicate that pore throat of a reservoir has little isolation due to different compositions with moderate to small in size, moderate throat and moderate to good connectivity (Figs. 7a, a'; b, b'; c, $\left.\mathrm{c}^{\prime} ; 8 \mathrm{c}, \mathrm{e}, \mathrm{f}, \mathrm{i}\right)$. Calculated porosity from different samples ranges from $5.3 \%$ to $21.1 \%$ that is shown in Table 3 .

\subsection{Porosity and permeability}

Pore voids play a significant role in enhancing the reservoir quality. The Es1 sandstone mostly consists of moderate to high porosity and permeability. On the basis of core observation and thin-section study, it has been revealed that Es1 sandstone containing primary intergranular pores along with secondary pores and occasionally microcrystalline pores is also present. Some of them are generated genetically after deposition as a result of dissolution and fracturing. Secondary pores are produced by different fluids that affect the unstable rock fragments and cement that entirely or partially dissolve the grains and pore cement (Figs. 5e; 8a). Dissolution pores are mostly generated in unstable detrital grains due to their low resistance against the acidic fluid. Petrophysical Es1 sandstone has an excellent primary porosity ranging from $0.4 \%$ to $32 \%$ and permeability ranging from 0.005 to $6870 \mathrm{mD}$ (Fig. 9). Secondary porosity caused by dissolution and fracture also enhances the reservoir porosity up to $5 \%$. Primary intergranular porosity accounts consist of the main reservoir space for $44 \%$ of the total reservoir space. Moreover, some feldspar/rock fragment dissolution pores $(27 \%)$, cement dissolution pores $(8 \%)$ and fractures pores (17\%) and fracture-dissolution pores $(6 \%)$ account for 57\% of the total reservoir space as shown in Fig. 10. Similarly, some other microfractures have specific reservoir characteristics, but they play a most vital role in serving oil and gas seepage channels to enhance the permeability of the reservoir.

Mineral dissolution occurred mainly during the uplift period, and the initial reburial stage, the uplift and development of fractures promoted the penetration of freshwater to these sandstones and also played an important role in enhancing the permeability of reservoir rock for fluid flow.

Table 3 Pore parameter from $\mathrm{N}_{2}$ adsorption measurement

\begin{tabular}{|c|c|c|c|c|c|c|c|}
\hline Sample no. & Depth, m & Lithology & Porosity, \% & Permeability, mD & $\mathrm{SBET}, \mathrm{m}^{2} / \mathrm{g}$ & VBJH, $\mathrm{cm}^{3} / \mathrm{g}$ & $\begin{array}{l}\text { Average } \\
\text { pore size, } \\
\mu \mathrm{m}\end{array}$ \\
\hline $1-\mathrm{Np} 3-80$ & 4534.70 & Conglomerate sandstone & 13.6 & 149 & 403.94 & 1.54 & 15.492 \\
\hline $2-\mathrm{Np} 306 \mathrm{X} 1$ & 4223.35 & C sandstone & 16.7 & 442 & 330.30 & 2.00 & 14.416 \\
\hline $3-\mathrm{Np} 306 \mathrm{X} 1$ & 4220.76 & C sandstone & 15.9 & 340 & 346.04 & 1.94 & 12.170 \\
\hline $4-\mathrm{Np} 280$ & 3503.20 & M sandstone & 21.1 & 49.2 & 1504.41 & 2.00 & 4.575 \\
\hline $5-\mathrm{Np} 280$ & 3503.95 & F sandstone & 15.2 & 1.30 & 5240.19 & 1.36 & 0.467 \\
\hline 6-Np3-19 & 4232.59 & Siltstone & 10.4 & 0.313 & 5540.27 & 1.42 & 0.073 \\
\hline $7-\mathrm{Np} 2-15$ & 3617.00 & F sandstone & 6.3 & 0.0908 & 4658.23 & 0.76 & 0.110 \\
\hline $8-\mathrm{Np} 306 \mathrm{X} 1$ & 4234.20 & M sandstone & 7.2 & 0.701 & 2081.61 & 0.74 & 0.508 \\
\hline $9-\mathrm{Np} 306 \mathrm{X} 1$ & 4218.70 & M sandstone & 5.3 & 124 & 115.49 & 0.60 & 6.591 \\
\hline
\end{tabular}

SBET surface area using Brunauer-Emmett-Teller method (Brunauer et al. 1938), VBJH pore volume using Barrette-Joyner-Halenda (Barrett et al. 1951), $C$ coarse, $M$ medium, $F$ fine 
Porosity, \%

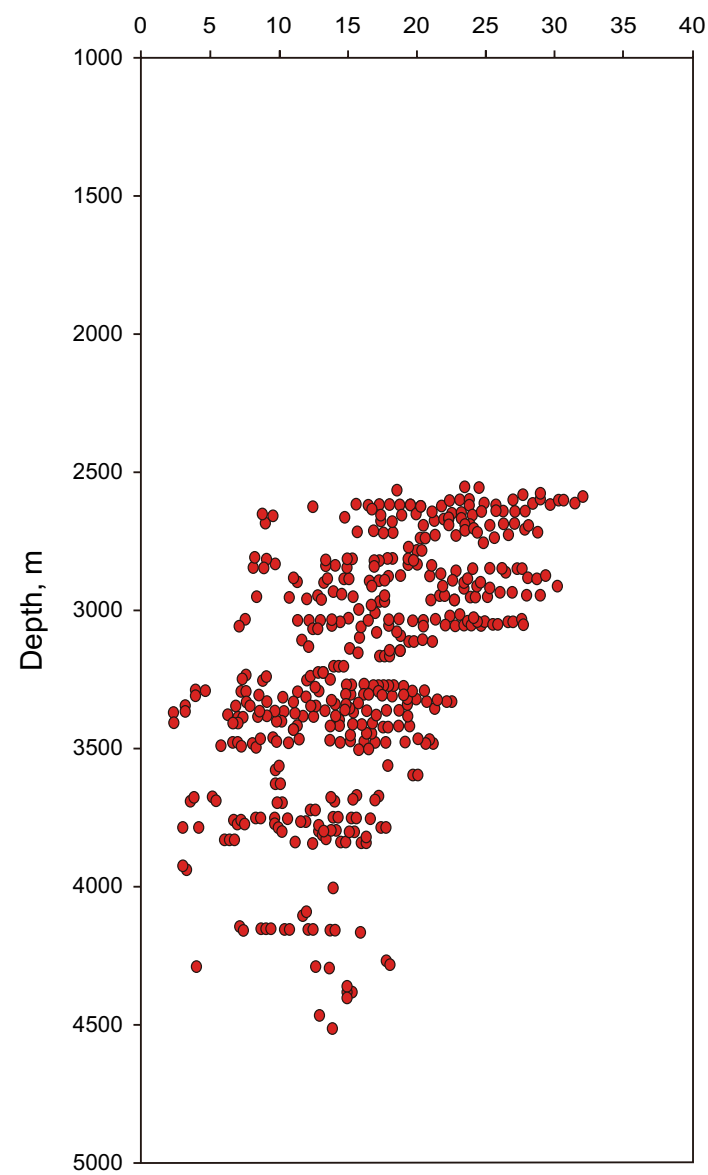

Permeability, $\mathrm{mD}$

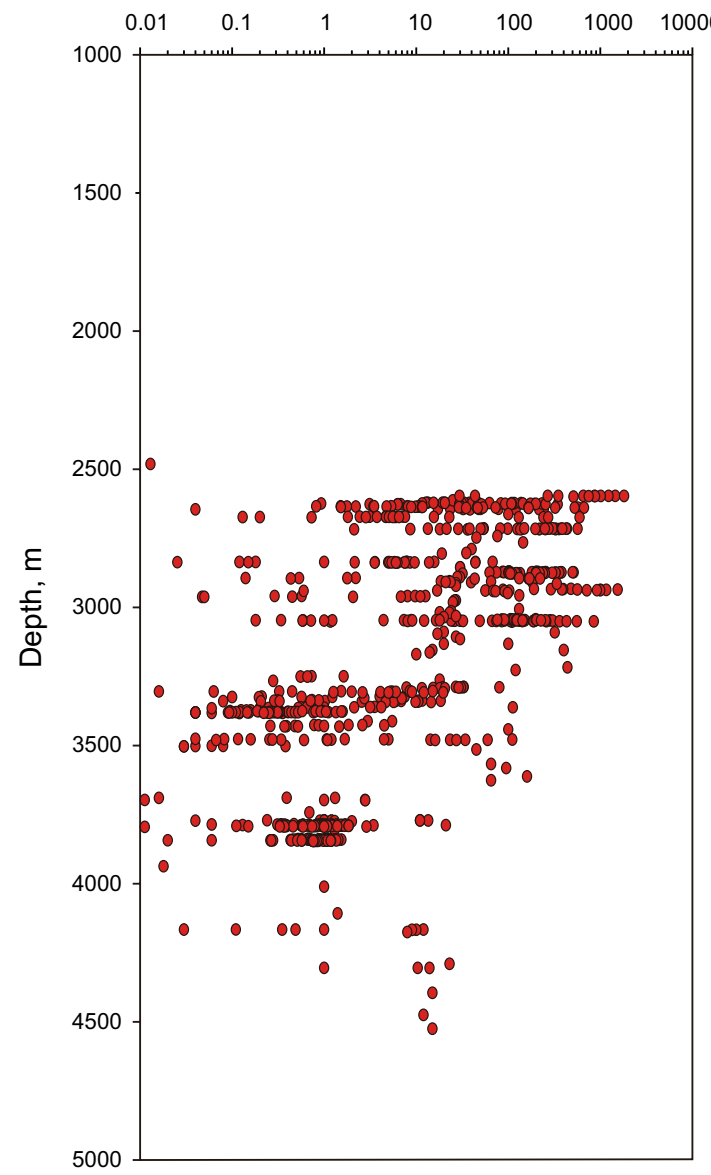

Fig. 9 Porosity and permeability distribution of different wells in Nanpu Sag

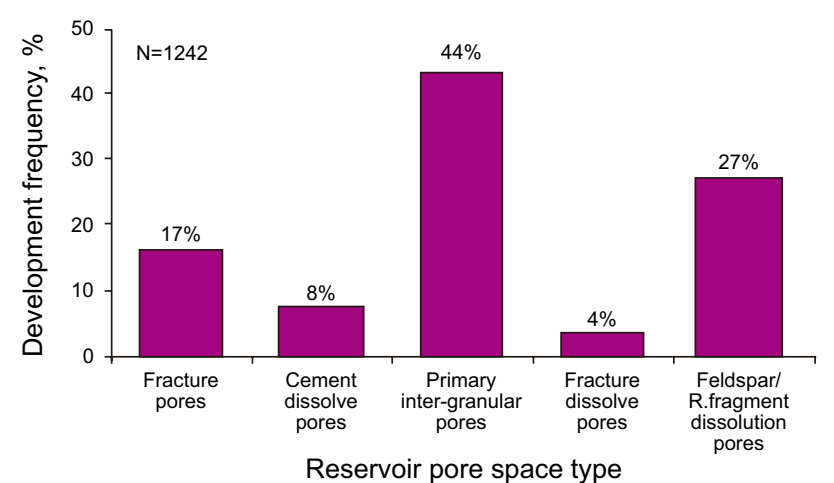

Fig. 10 Development frequency of different reservoir spaces within Shahejie Formation reservoir sandstone

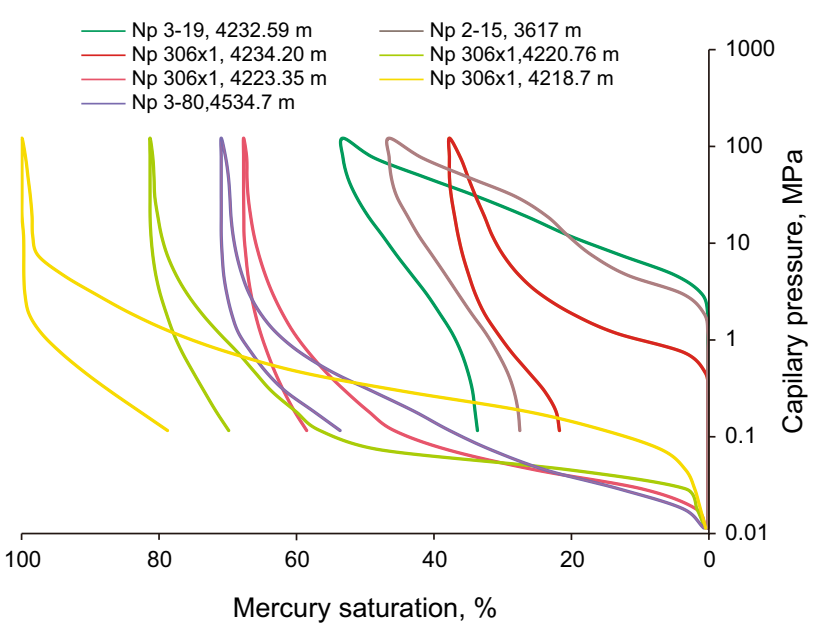

Fig. 11 Mercury saturation versus capillary pressure diagram in Nanpu well. MICP injection-withdrawal capillary curves on selected samples 


\section{Discussion}

\subsection{Relationship between sedimentary features and pore structures}

The relationship between depositional fabric and reservoir pore structures was evaluated by grain size analysis and sorting coefficient (So) and their correlation with pore structures. The reservoir permeability of Es1 sandstone is directly/positively related to grain size. This relation shows that the porosity is directly connected to rock fabric (grain size, grain shape and orientation). Generally, the compaction effect is adverse on coarse-grained sandstone that may lead to more efficient pore preservation and with increasing stress less effect on porosity reduction. In medium- to coarse-grained sandstone, it will result in the improvement of the connectivity of pores/permeability as compared to fine-grained rocks (Fawad et al. 2010) and pore throat size is also affected by grain size; the Es1 sandstone with medium-grained sandstone, coarse-grained sandstone and conglomerate sandstone has good pore and pore throat size. Coarse-grained rocks are consisting of coarser particles/fragments that provide a framework that is sufficiently strong to preserve relatively large pores at the high-stress area (Yang and Aplin 2007), whereas smaller pores accompany finegrained rocks. There is a positive and slight negative correlation between grain size and average pore diameter obtained from the $\mathrm{N}_{2}$ adsorption experiment. Fractures influence some grains during various structure experiments. Pore connectivity and throat size are higher due to fractures, whereas high surface area is obtained due to the clay matrix (Fig. 11).

\subsection{Mineral composition association with a pore structure}

Thin-section studies and XRD data represent that carbonates, clay minerals (kaolinite, illite-smectite, illite and chlorite), detrital quartz and feldspar are the most common minerals in the selected, studied samples (Figs. 5a, c, d, e; 8f). The link between mineral types, their amount and pore structures as well as the relationship between detrital minerals like quartz and feldspar, and other pore structure parameters are similar to carbonate minerals. That shows a link between pore structure parameter and carbonate and clay mineral contents used to study the mineral/pore structure relation, respectively. There is no negative correlation between carbonate minerals and clay minerals with permeability that
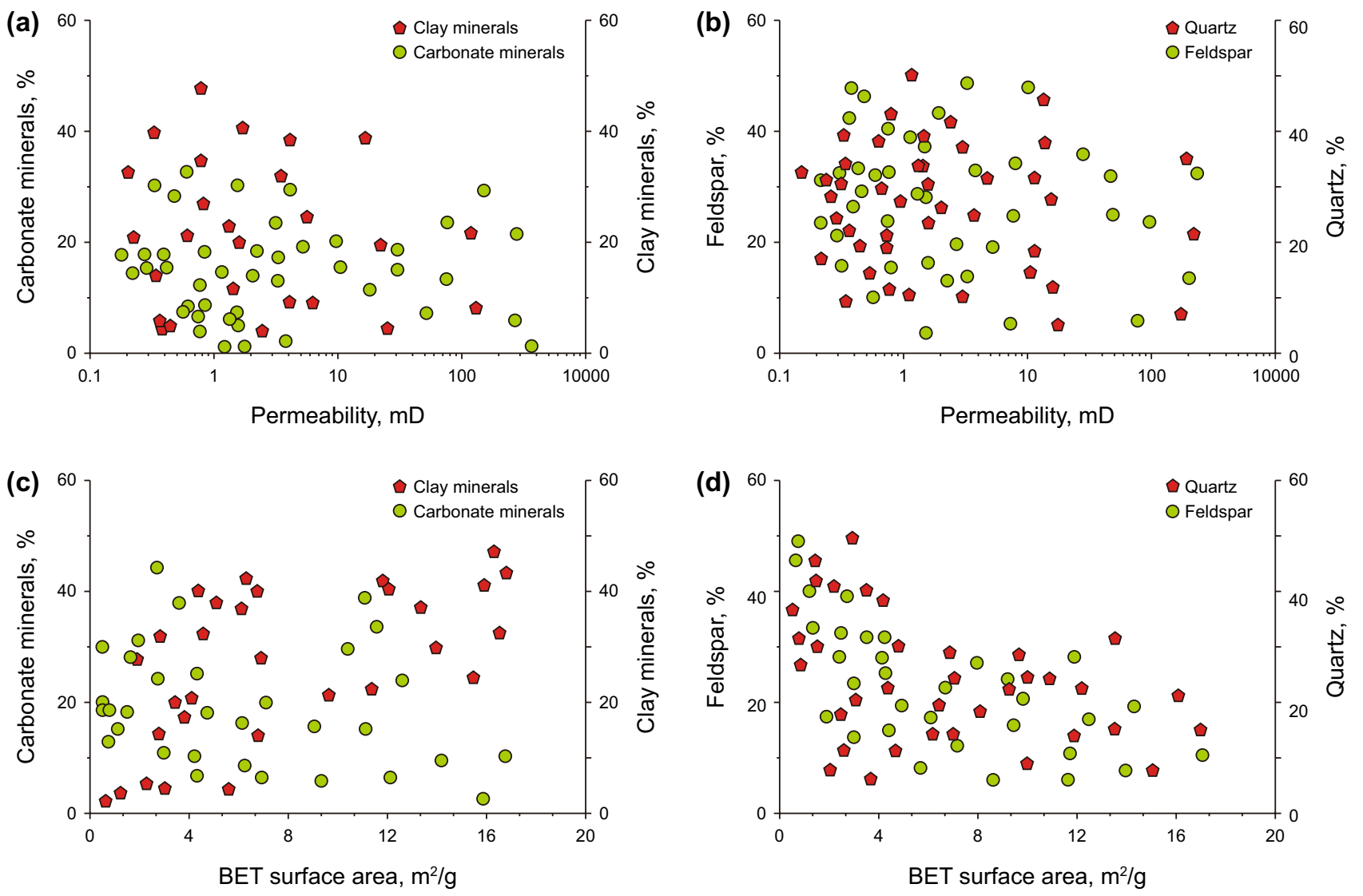

Fig. 12 Relation between mineral contents and pore structure parameter in Es1 sandstone 
is shown in Fig. 12a; rather, carbonate mineral has a very unpredictable effect on permeability; therefore, there is no clear correlation, particularly for Fig. 12a. Carbonate mineral has a very subtle correlation with permeability. It is neither a positive nor a negative correlation. Carbonate minerals have a patchy effect on permeability as data are very scattered. Generally, it should have a negative effect, but the studied selected sample data do not represent it. Clay mineral has a negative correlation in Fig. 12a with permeability. Scattering is due to random sampling. Similarly, Fig. 12c shows the meagre positive correlation between carbonate and clay minerals with BET surface area. It shows a very poor correlation between the carbonate and BET, either it is positive or negative, whereas clay minerals have a subtle positive correlation.

Clastic minerals like quartz and feldspar have a positive effect on reservoir properties as shown in Fig. 12b. Microscopic pore images and SEM studies of the pore are related to carbonate and clay minerals that show variability. After burial various diagenetic processes started on deposited sediments and due to compaction phenomenon, quartz, feldspar and carbonate minerals play a significant role in preserving the primary pores due to rigid framework and pressure shadow of rigid grain protect primary pores to collapse, whereas the presence of carbonate cement blocks the pore voids and blocks the pore throat. Intergranular and intragranular pores are associated with clay minerals that block the large pores between the grains and applying the negative effect on reservoir characteristics. However, there will be a positive relation between BET surface area and clay minerals, whereas quartz, feldspar, carbonate minerals and BET surface area show a variable association (Fig. 12c, d). The specific surface area of the sample is measured by Brunauer, Emmett and Teller (BET) including pore size distribution. It measures the surface area and open pores of macroporous and mesoporous material, as well as pore volume and area distribution that characterize porosity below the effective range of mercury intrusion. The SBET (specific surface area) of selected samples was calculated by the BET equation, and its values range from 5540.27 to $115.49 \mathrm{~m}^{2} / \mathrm{g}$. The specific pore volume values range from 2.0 to $0.073 \mathrm{~cm}^{3} / \mathrm{g}$. Clay contents are present in the studied sandstone as muddy interlayers and also present in siltstone and mudstone. Higher content of clay/mud increased the measured SBET and total pore volume due to high clay specific surface area. Micropores developed due to clogging of clay minerals segmenting of primary intergranular pores into micropores. Siltstone and fine-grained sandstone association with SBET and total pore volume suggest that carbonate minerals like quartz and feldspar are not a major contributor to total surface area and micropore volume (Figs. 7d, e, f; $8 \mathrm{~g}, \mathrm{~h}, \mathrm{i})$. In the studied area, carbonate mineral may provide relatively less total pore volume and specific surface area.

\subsection{The relation between routine core analysis and pore characteristics}

Mercury injection capillary pressure (MICP) test was conducted for routine core analysis in an experiment to relate the much costly mercury achieved as a result to routine less expensive, common and valid tests. MICP is a valuable technique to evaluate the pore throat size distribution as well as reservoir quality and diagenesis impact (Tavakoli et al. 2011). The calculated mean helium porosity ( $\varnothing \mathrm{He} \%$ ) of Es 1 sandstone shows very good porosities $(9.3 \%-27.1 \%)$ that are mentioned in Table 4 , and the measured helium $(\varnothing \mathrm{He} \%)$ porosity usually is higher than mercury porosity $(\varnothing \mathrm{Hg} \%)$. Both types of porosities are higher in Es1 sandstone, varying from base to middle and then top depending on carbonate cement and clay contents. The bulk permeability was

Table 4 Storage capacity properties of the Es1 sandstone of Shahejie Formation obtained from the routine core analysis and permeability values calculated from the mercury injection test

\begin{tabular}{lllllccccc}
\hline Sample no. & Depth, $\mathrm{m}$ & $\varnothing \mathrm{He}, \%$ & $\mathrm{r} 25, \mu \mathrm{m}$ & $\mathrm{Kr} 25, \mu \mathrm{m}$ & $\mathrm{R} 35, \mu \mathrm{m}$ & $\mathrm{Kr} 35, \mathrm{mD}$ & $\mathrm{r} 10, \mu \mathrm{m}$ & $\mathrm{Kr} 10, \mathrm{mD}$ & $\mathrm{Kb}, \mathrm{mD}$ \\
\hline Np3-80 & 4534.70 & 16.5 & 1.02 & 16.7 & 3.4 & 16.4 & 7.3 & 123.6 \\
Np306X1 & 4223.35 & 20.7 & 6.7 & 240 & 9.1 & 121.2 & 12.2 & 376.4 \\
Np306X1 & 4220.76 & 21.9 & 7.3 & 365 & 10.5 & 116.5 & 10.6 & 330.5 & 249 \\
Np280 & 3503.20 & 27.1 & 9.4 & 256 & 6.4 & 2.4 & 8.7 & 46.7 \\
Np280 & 3503.95 & 20.2 & 12.2 & 216 & 2.1 & 0.004 & 0.07 & 1.5 \\
Np3-19 & 4232.59 & 16.4 & 7.6 & 180 & 5.4 & 0.0034 & 0.05 & 1 & 1 \\
Np2-15 & 3617.00 & 10.3 & 5.8 & 245 & 1.003 & 0.005 & 0.004 & 0.98 \\
Np306X1 & 4234.20 & 12.2 & 5.1 & 175 & 1.5 & 0.023 & 0.032 & 0.76 & 6.313 \\
Np306X1 & 4218.70 & 9.3 & 6.2 & 256 & 8.5 & 15.7 & 7.4 & 132 & 5.70908 \\
\hline
\end{tabular}

$\phi H e$ mean porosity measured by helium injection, $r 25$ pore throat size corresponding to the 25 th percentile, $R 35$ pore throat size corresponding to the 35 th percentile, $K r 25$ calculated permeability at $\mathrm{r} 25, \mathrm{Kr} 35$ calculated permeability at R35, r 10 pore throat size corresponding to the 10 th percentile of measured mercury porosity, $K r 10$ calculated permeability at r10 using mercury porosity, $k b$ average uncorrected measured air permeability 
measured by air injection. Its values range from $5.70 \mathrm{mD}$ to $840 \mathrm{mD}$. The uncorrected air permeability was calculated on the basis of the equation of Winland (Kolodzie 1980) and Pittman (1992), where the usage of corrected permeability values, which may be trivial, would produce a deceptively small pore aperture size calculation (Pittman 2001).

The incorporation of porosity and permeability data in terms of reservoir quality index (RQI) data is suitable for use with the routine core analysis data that provide an excellent improvement in addressing the reservoir quality in different scales (Lai et al. 2016; Tavakoli et al. 2011). It is the best macrophysical factor for an assessable description of reservoir microscopic pore structure. Higher reservoir quality index (RQI) values indicate better microscopic pore structures (Lai et al. 2016). The concept of Amaefule et al. (1993) technique is based on the calculation of RQI, demarcated as follows:

$\mathrm{RQI}=\sqrt{\frac{k}{\varphi}}$,

where RQI is the reservoir quality index, $\mu \mathrm{m}$; $k$ is the permeability, $\mathrm{mD}$; and $\varphi$ is the porosity in terms of total volume fraction, $\%$.

Reservoir quality index (RQI) provides an appropriate starting point to address the differences between core plug samples and reservoir zones (Lai et al. 2016). RQI can be used to calculate the flow characteristics of reservoirs and provide a functional association between microscopic features and macroscopic logs (Lai et al. 2016). Reservoir heterogeneity concerning the variants in microscopic pore structure and reservoir macroscopic permeability of the core plug samples can be evaluated by RQI (Lai et al. 2016). The RQI and permeability values increase as the proportion of large pores and small pores increases. There is a significant variation in the pores, and the pore structures are complicated due to firm heterogeneity (Zhang et al. 2007). Pores and pore throats are affected by sediments, diagenetic interaction and cementation. RQI is a good representative of porosity and permeability reservoir quality indices, but this index is not suitable for the size distribution of pore throats (Tavakoli et al. 2011). This type of distribution could disclose the effect of diagenetic events on these two significant factors.

The measured permeability was plotted contrary to the mercury porosity differentiated into supercapillary pores/ megapores, capillary pores/mesopores and macropores and sub-capillary pores/micropores (Fig. 6). The supercapillary pores (megapores) establish an insignificant part of the total pore volume and characterize a surface effect that may be mixed with the conformance volume. That is why, these should be detached from additional deliberation, i.e. permeability is mostly contributed by the pores in the mesopores and macropores/capillary pores. An increase in the volume percentile increment of the sub-capillary micropore fraction escorts a decrease in the macropore and mesopore

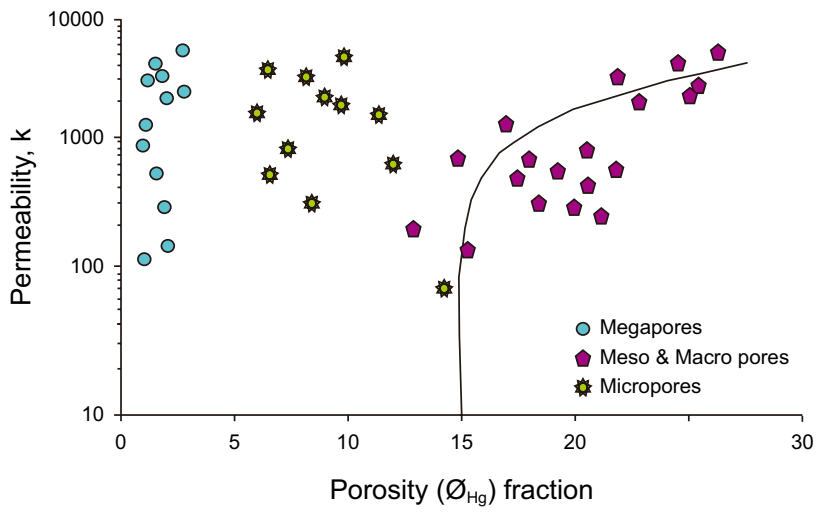

Fig. 13 Measured mercury porosity volume (\%) versus permeability (k) differentiated into megapore, macropore and micropore throat size

effective pore throats, which constitutes the most operative and permeable pore spaces, thus reducing the net permeability values (Fig. 13). Fine-grained sandstone, siltstone and mudstone consist of sub-capillary pores. The number of pores is high, but their connectivity is low due to their smaller size volume concerning coarse-grained sandstone. So the permeability of such rocks or part of the rock that consists of siltstone, mud presence and carbonate cement has low reservoir characteristics.

\subsection{Relationship between pore structure parameter and physical property}

The maximum and average pore throat radii are correlated to some extent with porosity and permeability. The better correlation for permeability as compared to porosity plots relating to pore structure parameters and physical properties is shown in Fig. 14a-d. The average pore throat radius signifies the better correlation with physical properties. It shows that the average pore throat radius distribution exemplifies the quality of the deeply buried sandstone reservoirs.

The pore throat distribution is directly reflected by the sorting coefficient of the throat (Sc), where smaller Sc is indicating the better sorted pore throat. The sorting coefficient shows a positive correlation with porosity and permeability as shown in Fig. 14e, f. The studied rock caused this positive correlation due to medium to coarse pores and pore throats; in addition, coarse pore throat, consisting of some microfractures, appears in samples with less sorted pores, so the coarser pore throat contributes much more to permeability. This complies with the pore structure characteristics discussed above, indicating that samples with large sorting coefficient have coarse pore throats that provide much more to permeability, whereas samples with smaller sorting coefficient have a large amount of more sorted small pores that account for a large porosity. 

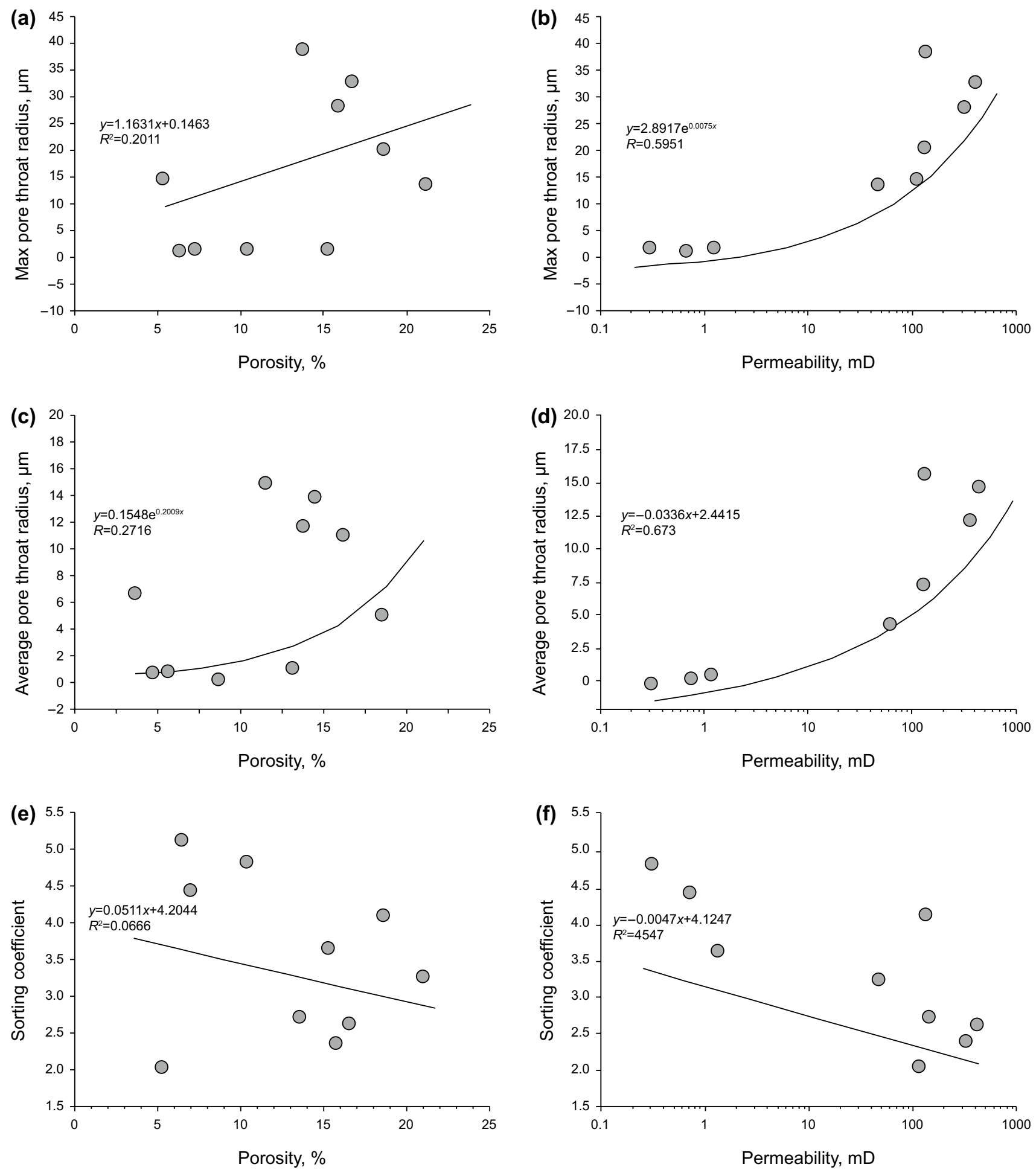

Fig. 14 Relationship between high-pressure mercury intrusion parameter and porosity and permeability

\section{Conclusion}

The Es1 sandstone of Shahejie Formation is mainly lacustrine sandstone with interbedded mudstone. The Es1 sandstone mostly consists of quartz, feldspar, rock fragments, clays minerals, mica minerals and carbonate minerals, and the rock is classified as feldspathic litharenite and lithic arkose.

Several types of pores are evaluated including primary intergranular pores, intragranular pores, dissolution pores, 
fractures pores, and it consists of several matrix pores and mineral pores including intergranular and intragranular pores. Pore throat system is characterized by MICP and LSCM, and a pore radius of the studied sandstone is in a wide range of $0.006 \mu \mathrm{m}$ to $>63 \mu \mathrm{m}$ depending on rock composition.

Medium- and coarse-grained sandstone consists of supercapillary to capillary pores, and pores are more prominent and suitably interconnected, so the porosity and permeability of such type of sandstone are high and sandstone, consisting of high reservoir characteristics. Finegrained sandstone, siltstone and mudstone are consisting of sub-capillary pores. They consist of abundant pores, but their connectivity is low due to their smaller size. So the permeability of such rocks or part of the rock that consists of siltstone, mud presence and carbonate cement has low reservoir characteristics.

Various minerals are having a different effect on pore structures of Es1 sandstone. Clastic minerals like quartz and feldspar have a positive impact on reservoir characteristics like porosity, permeability and pose size diameter, whereas carbonate mineral has a meagre effect on permeability and clay contents having vice versa relation. Sometimes with over $20 \%$ carbonates, permeability ranges from few $\mathrm{mD}$ to $100 \mathrm{mD}$, which shows no direct effect of carbonates. Larger pore throat is having a good effect on reservoir permeability, whereas fine-grained sandstone and siltstone consist of high porosity but low permeability.

Samples with large sorting coefficient have coarse pore throats that contribute much more to permeability, whereas samples with smaller sorting coefficient have a large amount of more sorted small pores that account for a large porosity.

Acknowledgements I would like to thank China University of Petroleum and China Scholarship Council (CSC) for granting a full scholarship (2015-2018) to carry out the research. This study was funded by the Natural Science Foundation of China Project (No. 41602138), National Science and Technology Special Grant (No. 2016ZX05006007), China Postdoctoral Science Foundation-funded Project (2015M580617; 2017T100524) and the Fundamental Research Funds for the Central Universities (15CX08001A). We would also like to thank the Jidong Oil Field Company for their cooperation to provide the research data and help to complete the research without loss of time. The reviewers are sincerely acknowledged for their helpful comments and suggestions on an earlier version of this manuscript. The authors are very thankful to the Associate Editor for his excellent advice and cooperation on a previous version of this manuscript.

Open Access This article is distributed under the terms of the Creative Commons Attribution 4.0 International License (http://creativeco mmons.org/licenses/by/4.0/), which permits unrestricted use, distribution, and reproduction in any medium, provided you give appropriate credit to the original author(s) and the source, provide a link to the Creative Commons license, and indicate if changes were made.

\section{References}

Allen MB, Macdonald DIM, Xun Z, Vincent SJ, Brouet-Menzies C. Early Cenozoic two-phase extension and late Cenozoic thermal subsidence and inversion of the Bohai Basin, northern China. Mar Pet Geol. 1997;14(7-8):951-72.

Amaefule JO, Altunbay M, Tiab D, Kersey DG, Keelan DK. Enhanced reservoir description: using core and log data to identify hydraulic (flow) units and predict permeability in uncored intervals/wells. In: SPE annual technical conference and exhibition. Society of Petroleum Engineers. 1993.

Bjørlykke K. Relationships between depositional environments, burial history and rock properties. Some principal aspects of diagenetic process in sedimentary basins. Sed Geol. 2014;301:1-14.

Barrett EP, Joyner LG, Halenda PP. The determination of pores volume and area distirbution in porous substances. I. Computation from nitrogen isotherms. J Am Chem Soc. 1951;73:373-80.

Brunauer S, Emmett PH, Telle E. Adsorption of gases in multimolecular layers. J Am Chem Soc. 1938;60:309-19.

Chalmers G, Bustin R, Powers I. A pore by any other name would be as small; the importance of meso- and microporosity in shale gas capacity. Denver, Colorado: AAPG Annual Convention and Exhibition; 2009. p. 1.

Chalmers GR, Bustin RM, Power IM. Characterization of gas shale pore system by porosimetry, pycnometry, surface area, and field emission scanning electron microscopy image analyses; example from the Barenett, Woodford, Haynesville, Marcellus, and Doig units. AAPG Bull. 2012;96:1099-119.

Chen F, Lu S, Chen F, Lu S, Ding X. Pore type and quantitative evaluation of pore volume in the Longmaxi Formation shale of southeast Chongqing, China. Acta Geol Sin (English Edition). 2018;92(1):342-53.

Chen L, Ji H, Zhang L, Jia H, Zhu Y, Fang Z. Effect of burial processes on the evolution of organic acids and implications for acidic dissolution from a case study of the Nanpu Sag, Bohai Bay Basin, China. J Nat Gas Sci Eng. 2017;39:173-87.

Chen C, Liu Y, Foley SF, Ducea MN, He D, Hu Z, Chen W, Zong K. Paleo-Asian oceanic slab under the North China craton revealed by carbonatites derived from subducted limestones. Geology 2016;44(12):1039-1042.

Clarkson CR, Bustin AM. Variation in micropores capacity and size distribution with composition in bituminous coal of the western Canadian sedimentary basin; implications for coalbed methane potential. Fuel. 1996;75(13):1483-98.

Clarkson CR, Solano N, Bustin A, Chalmers G, He L, Melnichenko YB, et al. Pore structure characterization of North American shale gas reservoir using USANS/SANS, gas adsorption, and mercury intrusion. Fuel. 2013;103:606-16.

Cook JE, Goodwin LB, Boutt DF. Systematic diagenetic changes in the grain-scale morphology and permeability of a quartz-cemented quartz arenite. AAPG Bull. 2011;95(6):1067-88.

Dickson JAD. Carbonate identification and genesis revealed by staining. J Sediment Pet. 1966;36(2):491-505.

Dong Y, Xiao L, Zhou H, Wang C, Zheng J, Zhang N, et al. The tertiary evolution of the prolific Nanpu Sag of Bohai Bay Basin, China: constraints from volcanic records and tectono-stratigraphic sequences. GSA Bull. 2010;122:609-26.

Fawad M, Mondol NH, Jahren J, Bjorlykke K. Microfacies and rock properties of experimentally compressed silt- clay mixtures. Mar Pet Geol. 2010;27:1698-712.

Folk R. Petrology of sedimentary rocks. Austin: Hamphill; 1974. p. 182.

Gong Z. Giant offshore oil and gas fields in China. Beijing: Petroleum Industry Press; 1997 (in Chinese). 
Guo J, Xu J, Guo F, Li J, Pang X, Dong Y, et al. Functional-element constraint hydrocarbon distribution model and its application in the 3rd member of Dongying Formation, Nanpu Sag, Bohai Bay Basin, eastern China. J Pet Sci Eng. 2016;139:71-84.

Guo X, He S, Liu K, Song G, Wang X, Shi Z. Oil generation as the dominant overpressure mechanism in the Cenozoic Dongying depression, Bohai Bay Basin, China. AAPG Bull. 2010;94(12):1859-81.

Guo X, Liu K, He S, Song G, Wang Y, Hao X, et al. Petroleum generation and charge history of the northern Dongying Depression, Bohai Bay Basin, China: insight from integrated fluid inclusion analysis and basin modelling. Mar Pet Geol. 2012;32(1):21-35.

Guo Y, Pang X, Dong Y, Jiang Z, Chen D, Jiang F. Hydrocarbon generation and migration in the Nanpu Sag, Bohai Bay Basin, eastern China: insight from basin and petroleum system modeling. J Asian Earth Sci. 2013;77:140-50.

Howard JJ. Porosimetry measurement of shale fabric and its relationship to illite/smectite diagenesis. Clay Clay Miner. 1991;39:355-61.

Hao F, Zhou X, Zhu Y, Yang Y. Lacustrine source rock deposition in response to co-evolution of environments and organisms controlled by tectonic subsidence and climate, Bohai Bay Basin, China. Org Geochem. 2011;42(4):323-39.

Hollis C, Vahrenkamp V, Tull S, Mookerjee A, Taberner C, Huang Y. Pore system characterisation in heterogeneous carbonates: an alternative approach to widely-used rock-typing methodologies. Mar Pet Geol. 2010;27(4):772-93.

Jiang H, Wang H, Lin ZL, Fang XX, Zhao S, Ren GY. Periodic in rifting activity and its controlling on sedimentary filling of Paleogene period in Nanpu Sag. Acta Sedimentol Sin. 2009;27:976-82 (in Chinese with English abstract).

Kashif M, Cao Y, Yuan G, Jian W, Cheng X, Sun P, \& Hassan S. Diagenesis impact on a deeply buried sandstone reservoir (Es1 Member) of the Shahejie Formation, Nanpu Sag, Bohai Bay Basin, East China. Aust J Earth Sci. 2019;66:133-151.

Kashif M, Cao YC, Yuan G, Jian W, Cheng X, Sun P, et al. Diagenesis impact on a deeply buried sandstone reservoir (Es1 Member) of the Shahejie Formation, Nanpu Sag, Bohai Bay Basin, East China. Aust J Earth Sci. 2018;66:1-19.

Loucks RG, Dodge MM, Galloway WE. Regional controls on diagenesis and reservoir quality in lower Tertiary sandstones along othe Texas Gulf Coast: Part 1. Concepts and principles, 1984;15-45.

Loucks RG, Reed RM, Ruppel SC, Hammes U. Spectrum of pore types and network in mudrocks and a descriptive classification for matrix-related mudrock pores. AAPG Bull. 2012;96:1071-98.

Lai J, Wang G, Wang S, Cao J, Li M, Pang X, et al. Review of diagenetic facies in tight sandstones: diagenesis, diagenetic minerals, and prediction via well logs. Earth Sci Rev. 2018a;185:234-58.

Lai J, Wang G, Fan Z, Chen J, Wang S, Zhou Z, et al. Insight into the pore structure of tight sandstones using NMR and HPMI measurements. Energy Fuels. 2016;30(12):10200-14.

Lai J, Wang G. Fractal analysis of tight gas sandstones using highpressure mercury intrusion techniques. J Nat Gas Sci Eng. 2015;24:185-96.

Lai J, Wang G, Cai C, Fan Z, Wang S, Chen J, et al. Diagenesis and reservoir quality in tight gas sandstones: the fourth member of the Upper Triassic Xujiahe Formation, Central Sichuan Basin, Southwest China. Geol J. 2018b;53(2):629-46.

Lai J, Wang G, Cao J, Xiao C, Wang S, Pang X, et al. Investigation of pore structure and petrophysical property in tight sandstones. Mar Pet Geol. 2018c;91:179-89.

Mozley PS, Heath JE, Dewers TA, Bauer SJ. Origin and heterogeneity of pore sizes in the Mount Simon Sandstone and Eau Claire Formation: implications for multiphase fluid flow. Geosphere. 2016;12(4):1341-61.
Mondol NH, Bjorlykke K, Jahren J, Hoeg K. Experimental mechanical compaction of clay minerals aggregates: changes in physical properties of mudstones during burial. Mar Pet Geol. 2007;24:289-311.

Nabawy BS, Geraud Y, Rochette P, Bur N. Pore-throat characterization in highly porous and permeable sandstone. AAPG Bull. 2009;93:719-39.

Pittman ED. Relationship of porosity and permeability to various parameters derived from mercury injection capillary pressure curve for sandstone. AAPG Bull. 1992;76:191-8.

Pittman ED. Estimating pore throat size in sandstone from routine core-analysis data: search and discovery article 40009.2001. http://www.searchanddiscovery.net/documents/pittman/index.htm. Accessed 27 Mar 2007.

Ross DJ, Bustin RM. The importance of shale composition and pore structures upon gas storage potential of shale gas reservoir. Mar Pet Geol. 2009;26:916-27.

Rexer TF, Mathia EJ, Aplin AC, Thomas KM. High pressure Methane adsorption and characterization of pores in Posidonia shales and isolated kerogene. Energy Fuels. 2014;28:2886-901.

Rouquerol J, Avnir D, Fairbridge C, Everett D, Haynes J, Pernicone N, et al. Recommendation for the characterization, of porous solids (technical report). Pure Appl Chem. 1994;66:1739-58.

Rose W, Bruce WA. Evaluation of capillary character in petroleum reservoir rock. J Pet Technol. 1949;1(05):127-42.

Ren J, Tamaki K, Li S, Junxia Z. Late Mesozoic and Cenozoic rifting and its dynamic setting in Eastern China and adjacent areas. Tectonophysics. 2002;344(3-4):175-205.

Saiag J, Brigaud B, Portier E, Desaubliaux G. Sedimentological control on the diagenesis and reservoir quality of the tidal sandstone of the Upper Cap Hay Formation (Permian, Bonaparte Basin, Australia). Mar Pet Geol. 2016;77:597-624.

Song GQ, Jiang YL, Liu H, Cai DM. Pooling history of cracked gas in middle-deep reservoirs in Lijin-Minfeng areas of the Dongying sag. Nat Gas Ind. 2009;29(4):14-7.

Schmitt M, Fernandes CP, da Cunha Neto JA, Wolf FG, dos Santos VS. Characterization of pore systems in seal rocks using nitrogen gas adsorption combined with mercury injection capillary pressure techniques. Mar Pet Geol. 2013a;39:138-49.

Samakinde C, Opuwari M, van Bever Donker J M. The effects of clay diagenesis on petrophysical properties of the lower Cretaceous sandstone reservoirs, Orange Basin, South Africa. S Afr J Geol. 2016;119(1):187-202.

Soeder DJ, Chowdiah P. Pore geometry in high- and low-permeability sandstones, Travis Peak Formation, East Texas. SPE Form Eval. 1990;5(04):421-30.

Schmitt M, Fernandes CP, da Cunha Neto J A, Wolf FG, dos Santos VS. Characterization of pore systems in seal rocks using nitrogen gas adsorption combined with mercury injection capillary pressure techniques. Mar Pet Geol. 2013b;39(1):138-49.

Schmitt M, Fernandes CP, Wolf FG, da Cunha Neto J A B, Rahner $\mathrm{CP}$, dos Santos VSS. Characterization of Brazilian tight gas sandstones relating permeability and Angstrom-to micron-scale pore structures. J Nat Gas Sci Eng. 2015;2:785-807.

Tavakoli V, Rahimpour-Bonab H, Esrafili-Dizaji B. Diagenetic controlled reservoir quality of South Pars gas field, an integrated approach. CR Geosci. 2011;343(1):55-71.

Taghavi AA, Mørk A, Emadi MA. Sequence stratigraphically controlled diagenesis governs reservoir quality in the carbonate Dehluran Field, southwest Iran. Pet Geosci. 2006;12(2):115-26.

Tian H, Pan L, Zhang T, Xiao X, Meng Z, Huang B. Pore characterization of organic-rich lower Cambrian shales in Qiannan depression of Guizhou province, Southwestern China. Mar Pet Geol 2015;62:28-43.

Vavra CL, Kaldi JG, Sneider RM. Geological applications of capillary pressure: a review (1). AAPG Bull. 1992;76(6):840-50. 
Xu AN, Dong YX, Zou CN, Wang ZC, Zheng HJ, Wang XD, et al. Division and evaluation of oil-gas prolific zones for lithostratigraphic reservoirs in the Nanpu Sag. Pet Explor Dev. 2008a;35(3):272-80.

Xie X, Fan Z, Liu X, Lu Y. Geochemistry of formation water and its implication on over pressured fluid flow in the Dongying depression of the Bohaiwan Basin, China. J Geochem Explor. 2006;89(1-3):432-5.

Xu QQ, Ji JQ, Wang JD, Wang ZL, Han WG, Yu JG. Active mode of the Tan-Lu fault zone in early Cenozoic. Chin J Geol. 2008b;43(2):402-14.

Wang H, Wang F, Zhou H, Dong Y. Thermal evolution dynamics of Nanpu Sag, Bohai Bay Basin, and its hydrocarbon accumulation dynamics. Wuhan: China University of Geosciences Press; 2002 (in Chinese with English abstract).

Wang YZ. Genetic mechanism and evolution model of secondary pore development zone of Paleogene in the north zone in Dongying depression. Qingdao: China Univ Pet (Huadong); 2010.

Xi K, Cao Y, Haile BG, Zhu R, Jahren J, Bjørlykke K, Zhang X, Hellevang, $\mathrm{H}$. How does the pore-throat size control the reservoir quality and oiliness of tight sandstones? The case of the Lower Cretaceous Quantou Formation in the southern Songliao Basin, China. Mar Petr Geol 2016;76:1-15.

Yang Y, Aplin AC. Permeability and petrophysical properties of 30 natural mudstones. J Geophys Res: Solid Earth. 2007;112(B3):2007.

Yuan G, Gluyas J, Cao Y, Oxtoby N, Jia Z, Wang Y, Li X. Diagenesis and reservoir quality evolution of the Eocene sandstones in the northern Dongying Sag, Bohai Bay Basin, East China. Mar Pet Geol 2015;62:77-89.

Yue D, Wu S, Xu Z, Xiong L, Chen D, Ji Y, et al. Reservoir quality, natural fractures, and gas productivity of upper Triassic Xujiahe tight gas sandstones in western Sichuan Basin, China. Mar Pet Geol. 2018;89:370-86.

Zhang S, Cao Y, Jahren J, Zhu R, Mao Z, Xi K, et al. Pore characteristics of the fine-grained tight reservoirs in the Yabulai Basin, Northwestern China. Acta Geol Sin (English Edition). 2018;92(3):1170-92.

Zhu G, Jin Q. Geochemistry characters study of two sets of high quality source rock in Dongying Sag. Acta Sedimentol Sin. 2003;21:50612 (in Chinese).

Zhang Q, Zhu X, Steel RJ, Zhong D. Variation and mechanisms of clastic reservoir quality in the Paleogene Shahejie Formation of the Dongying Sag, Bohai Bay Basin, China. Pet Sci. 2014;11(2):200-10.

Zhang LH, Zhou CC, Liu GQ, Liu ZH, Zhang L. Origin and property differences of various types of low-porosity and low-permeability reservoirs and well logging evaluation strategies. Shiyou Kantan Yu Kaifa (Pet Explor Dev). 2007;34(6):702-10.

Zou C, Zhu R, Liu K, Su L, Bai B, Zhang X, et al. Tight gas sandstone reservoirs in China: characteristics and recognition criteria. J Pet Sci Eng. 2012;88:82-91. 